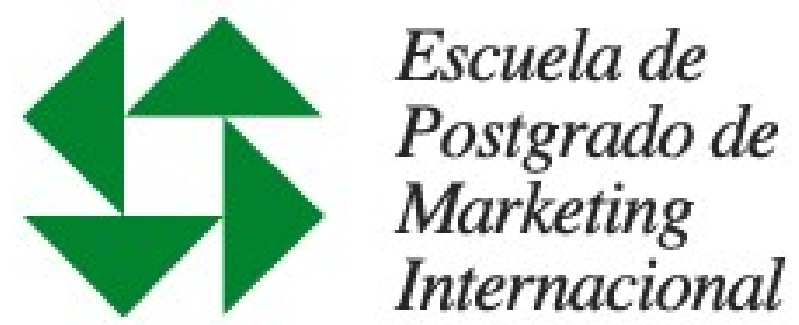

\title{
Marketing Transcultural en Marcas Sustentables como Estrategia de Empresas Multinacionales
}

Trabajo Científico libre para la obtención del grado de Magister en Marketing Internacional de la Escuela de Postgrado de Marketing Internacional-

Facultad de Ciencias Económicas

- Universidad Nacional de La Plata -

Profesor Director de la Tesis:

Prof. Dra. Cristina Zapata
Presentada por:

Paola Chandler

270 Av. San Juan

Capital Federal Buenos Aires 


\section{AGRADECIMIENTO}

En primer lugar y por sobre todas las cosas, agradezco a mis padres, hermanos y novio, quienes han sido la base fundamental de este logro, al estar presentes en todo momento para apoyarme y alentarme.

A mi tutora, Dra. Cristina Zapata, por su dedicación constante, su profesionalismo y su infinita paciencia que han sido fundamentales para mi formación como investigadora.

A los profesores y compañeros de la maestría por compartir sus conocimientos y experiencias, dentro y fuera de las aulas de clase.

A todas aquellas personas que de una forma u otra contribuyeron para la realización de este trabajo de grado.

Gracias por todo.

Paola Chandler 


\section{ÍNDICE}

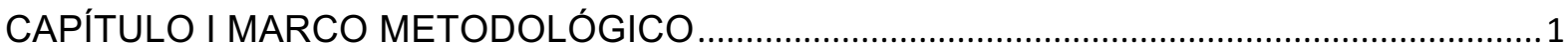

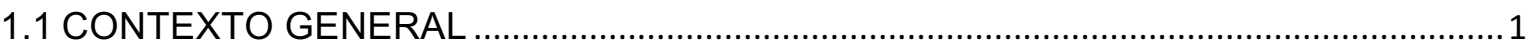

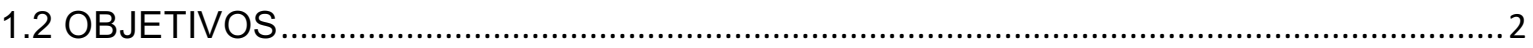

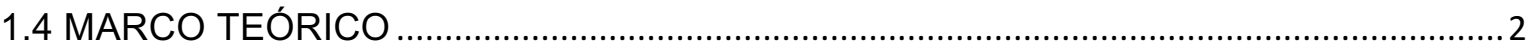

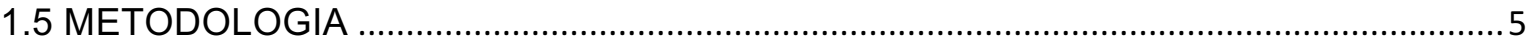

CAPÍTULO II CARACTERÍSTICAS DE LA TRANSCULTURALIDAD DE LA MARCA............6

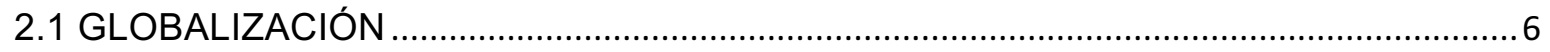

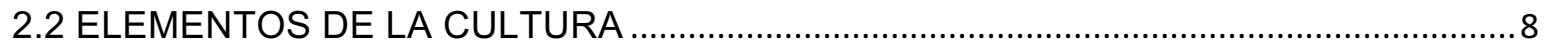

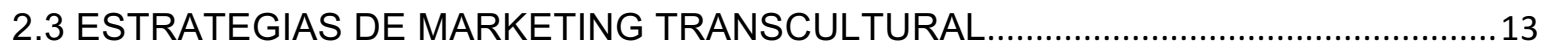

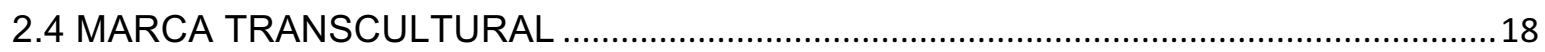

CAPÍTULO III SUSTENTABILIDAD EN LAS MARCAS DE PRODUCTOS

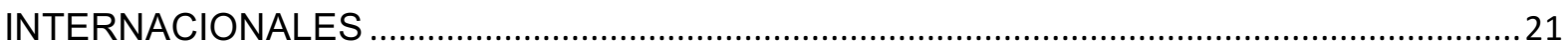

3.1 CARACTERÍSTICAS DE LAS MARCAS SUSTENTABLES .........................................21

3.2 CUALIDADES DEL MERCADO DE DEMANDA SUSTENTABLES...............................25

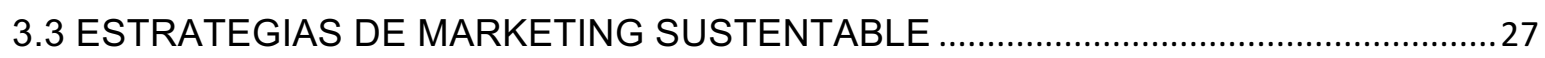

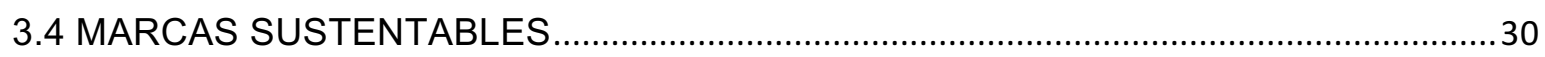

CAPÍTULO IV PLANIFICACIÓN DE LAS MARCAS INTERNACIONALES.............................33

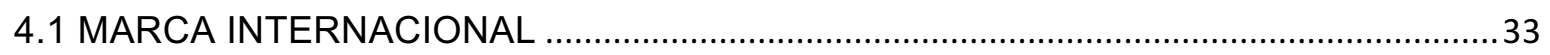

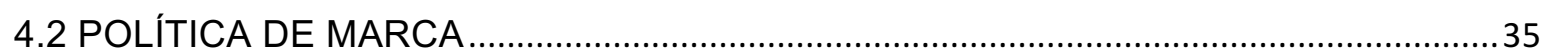

4.3 ESTRATEGIAS DE MARCA INTERNACIONAL SUSTENTABLES................................. 38

CAPÍTULO V SUSTENTABILIDAD EN LAS MARCAS DE PRODUCTOS

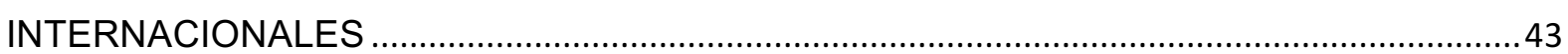

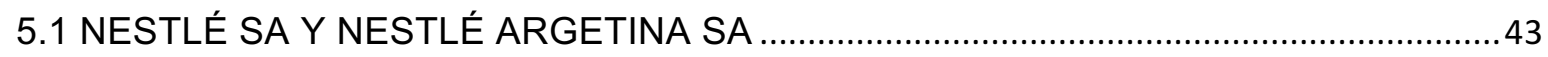

5.1.1. EFICIENCIA Y USO RACIONAL DE LOS RECURSOS ......................................... 44

5.1.2 COMPROMISO CON LOS DERECHOS HUMANOS ................................................. 45

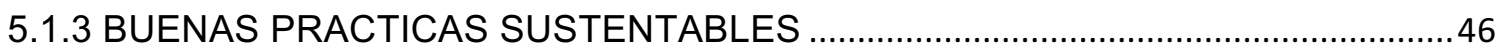

5.1.4 POLÍTICAS Y ESTRATEGIAS DE SUSTENTABILIDAD NESTLÉ ARGENTINA SA

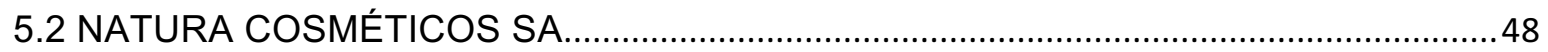

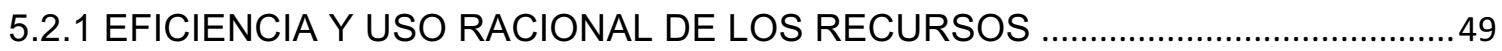

5.2.2 COMPROMISO CON LOS DERECHOS HUMANOS ….............................................50

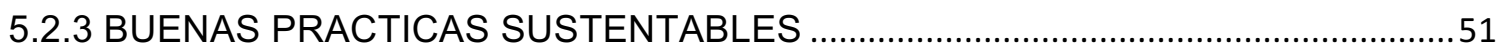

5.2.4 POLÍTICAS Y ESTRATEGIAS DE SUSTENTABILIDAD NATURA COSMÉTICOS

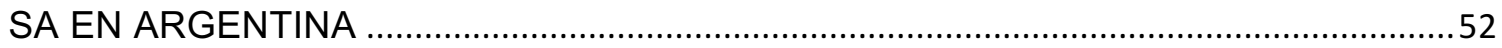

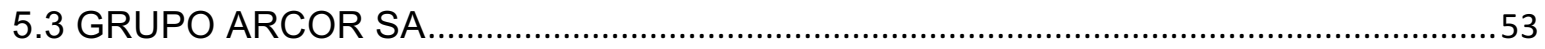

5.3.1 EFICIENCIA Y USO RACIONAL DE LOS RECURSOS .........................................54 
5.3.2 COMPROMISO CON LOS DERECHOS HUMANOS Y LABORALES .55

5.3.3 BUENAS PRÁCTICAS SUSTENTABLES ……………………………………....56

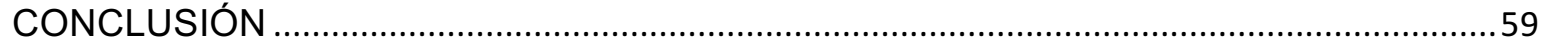

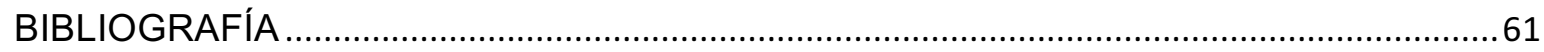




\section{CAPÍTULO I MARCO METODOLÓGICO}

\subsection{CONTEXTO GENERAL}

Las marcas sustentables están creciendo de forma acelerada en la actualidad, los nuevos consumidores son cada vez más conscientes y atentos de las acciones de las empresas con respecto a los productos que las compañías elaboran y los efectos negativos generados al planeta. Los consumidores alrededor del mundo se muestran cada vez más interesados en realizar acciones que ayuden a proteger y minimizar los daños al medio ambiente como también a las desigualdades sociales. Sin embargo, no es secreto que para poder realizar un cambio sustancial los consumidores, ameritan ayuda de entidades gubernamentales, empresas, y de todos los actores de la sociedad civil; los usuarios desean que las compañías fabriquen artículos que no solo protejan al medio ambiente, sino que a su vez cumplan con las funciones esenciales para lo cual fueron elaborados.

Hoy en día en el mundo, existe la cultura del reciclaje y la conservación de la biodiversidad. Las empresas internacionales se han percatado de la necesidad y el deseo de que tiene la demanda de adquirir productos ambientalmente seguros. Por tal motivo, las empresas han dirigido sus esfuerzos a transformar sus operaciones y actividades productivas a unas que consideren las variables sustentables. Para ello, han establecido políticas y estrategias responsables con el medio ambiente y la sociedad.

El marco metodológico abordará el contexto general que dio origen al presente estudio, así como los objetivos planteados, el marco teórico y mitológico conformando de esta manera el Capítulo I. Por su parte, en el Capítulo II, Características de la transculturalidad de la marca, se exponen las características de marca que trasciende las barreras culturales en los diferentes mercados en los que opera, el capítulo III Ilamado, Sustentabilidad en las marcas de productos internacionales que las bases que sirven de fundamento teórico definiendo los aspectos que debe poseer un producto o servicio para ser considerado sustentable, ha sido el segundo objetivo específico establecido.

En el capítulo IV, Planificación de las marcas internacionales, se describen los elementos y pasos necesarios para la creación una marca internacional. El capítulo $V$, Ejemplificación de Marcas Transculturales y Sustentables se desarrollarán tres marcas 
transculturales y sustentables de empresas internacionales, para describir las características y elementos que sustentan las teorías expresadas en los capítulos anteriores. Por último, se desarrollará el análisis e interpretación de las conclusiones derivadas de la investigación.

\subsection{OBJETIVOS}

\section{Objetivo General:}

- Revisar cómo las empresas multinacionales diseñan estrategias de marcas superadoras con impacto social.

\section{Objetivos Específicos:}

- Clasificar las características de la transculturalidad de la marca

- Cómo se distingue la sustentabilidad en las marcas de productos internacionales

- Describir las características de la planificación de las marcas

- Ejemplificar marcas internacionales que cumplan con los conceptos de transculturalidad y sustentabilidad

\subsection{MARCO TEÓRICO}

De acuerdo con Cepeda (2014) ${ }^{1}$ el consumo actualmente está representado por una relación entre disciplinas como la psicología, sociología, antropología, economía y la administración, que abarcan el estudio del comportamiento humano, la psiquis y otros aspectos de la naturaleza humana hasta la gestión administrativa y los procesos económicos. Esta relación interdisciplinaria influye en el marketing y por consiguiente en el concepto de marca y a su vez se alimenta de ellos. En este sentido, Schroeder $(2015)^{2}$ considera que la marca no solo es un símbolo o tipografía, sino que es un elemento del que emana una amplia gama de significados y valores, que cada individuo tiende a asociar con valores percibidos de forma independiente.

\footnotetext{
${ }^{1}$ Cepeda-Palacio, S.,(2014), Alcances actuales del concepto de marca. Un estudio comparativo, en la historia. Entramado,10(2), p.129

${ }^{2}$ Schroeder, J., (2015). Brands interdisciplinary perspective. Estados Unidos: Taylor and Francis Group. p 06
} 
Según Jiménez y Camirra $(2015)^{3}$ el estudio del comportamiento del consumidor abarca de manera particular a cada uno de los individuos que forman parte de la sociedad, tomando en cuenta que ellos en alguna oportunidad pasada o futura, han sido o serán consumidores. De modo que, estudiar a cada uno de estos individuos y por tanto los elementos que los estimulan a consumir, es un aspecto fundamental dentro del análisis del marketing actualmente. Marketing transcultural consiste en diseñar estrategias comerciales para que las compañías puedan acceder a nuevos mercados destinos y traspasar las diferencias culturales, creadas por los cambios de valores con los que se identifican sus clientes (Tharp, 2014) ${ }^{4}$

Los mercados internacionales pueden diferenciarse en cuanto a elementos como el desarrollo de marcas y el comportamiento del consumidor, sin embargo, la clave del éxito se encuentra en la disposición de adaptar los programas a la realidad de cada país (Llopis, 2015) ${ }^{5}$. Siendo estos los motivos, por los cuales académicos, investigadores de mercado y autores han trabajado constantemente en comprender de qué manera se desarrollan y acentúan los significados de las marcas en relación con las diferencias culturales.

Existen múltiples estudios que demuestran el incremento de conciencia en los clientes hacia temas como el daño ambiental. Son varios los autores que durante las últimas décadas han notado la creciente preocupación de la demanda internacional sobre el deterioro ambiental, lo cual ha impactado en el comportamiento de consumo de los usuarios (Moreno cita a Fraj y Martínez (2003) ${ }^{6}$. Por tal razón, estos valores deben ser reconocidos y estudiados por los profesionales del marketing y especialistas en marcas, considerando su influencia en la toma de decisión de la demanda (Cubillo y Blanco $2014)^{7}$.

Basado en la American Marketing Association (2015) ${ }^{8}$, "el marketing verde es la comercialización de productos que presumen ser ambientalmente seguros para el medio

\footnotetext{
${ }^{3}$ Jiménez, A; Camirra, H.,_(2015). Nuevas tendencias del mercadeo internacional: enfoque del branding y su vinculación con el consumidor. Economía. XL(40), p.184

${ }^{4}$ Tharp, M., (2014). Transcultural Marketing. New York, Estados Unidos: Taylor and Francis Group, p. 02

${ }^{5}$ Llopis Sancho, E.,(2015). Crear la Marca Global Modelo: práctico de creación e internacionalización de Marca. Madrid, España : ESIC, p. 102

${ }^{6}$ Moreno, H., (2014). La influencia del precio y las estrategias de comunicación visual basadas en simbología cultural sobre la preferencia de marcas ecológicas y consumo sostenible. EAN. (77), p.171

${ }_{7}^{7}$ Cubillo, J., Blanco, A.,(2014). Estrategias de Marketing Sectorial. Madrid, España: ESIC. p.74

${ }^{8}$ AMA. American Marketing Association, (2015). Recuperado 20 de Diciembre de 2018

https://www.ama.org/resources/Pages/Dictionary.aspx?dLetter=G
} 
ambiente y para su público meta". Del mismo modo, Sarkar $(2012)^{9}$ lo define como el conjunto de acciones realizadas por las diferentes áreas de la compañía, con el propósito de representar menor amenaza al medio ambiente. A su vez, indica que en la actualidad el marketing ecológico es considerado como el instrumento del desarrollo sostenible, consolidando las marcas que ofrecen esta propuesta de valor a los consumidores.

De modo que, recae en el sector empresarial la obligación de no solo implementar procesos productivos amigables con el medio ambiente, mediante programas de responsabilidad social creados para tal fin, sino también, el desarrollo e innovación en la fabricación y comercialización de productos ecológicos (Moreno, 2014) ${ }^{10}$. Para ello, es necesario implementar una cultura corporativa medioambiental, en la cual todos los integrantes trabajen con el propósito de atender las necesidades sociales, ambientales y económicas de los consumidores (Cubillo y Blanco, 2014) ${ }^{11}$.

Los especialistas en marketing han desarrollado varias formas para vincularse con los usuarios, apelando a estímulos racionales y emocionales (Hoyos, 2016) ${ }^{12}$. Hoy en día, existen marcas que se posicionan en los mercados, por sus atributos emocionales, utilizándolas como estrategias ecológicas (Moreno, 2014) ${ }^{13}$. Debido al creciente interés de los consumidores frente al deterioro medioambiental, comienzan a surgir movimientos en defensa del medio ambiente y de los derechos de los consumidores, que instan a los gobiernos y a sus instituciones a involucrar la variable del medio ambiente y su riesgo en sus decisiones relacionadas tanto al marketing, como a la producción y comercialización de productos bajo estándares ecológicos (Cubillo y Blanco, 2014) ${ }^{14}$.

Las estrategias de marketing verde pueden ser implementadas en diversas áreas de la empresa y de la composición del marketing mix, implicando las actividades integradas entre sí. Por su parte, Borin, Lindsey-Mullikin y Krishnan $(2013)^{15}$, estipulan tres

\footnotetext{
${ }^{9}$ Sarkar, A., (2012). Green Branding and eco-innovations for evolving a sustainable green marketing strategy. Asia-Pacific Journal of Management Research and Innovation. 8(1), p. 39. DOI: 10.1177/2319510X1200800106. Recuperado 21 de Enero de 2019.https://www.academia.edu/9238214/Green_Branding_and_Ecoinnovations for Evolving a Sustainable Green Marketing Strategy Innovation Additional services and information for ${ }^{10}$ Moreno, H., (2014). La influencia del precio y las estrategias de comunicación visual basadas en simbología cultural sobre la preferencia de marcas ecológicas y consumo sostenible. EAN. (77), p. 172

${ }^{11}$ Cubillo, J., Blanco, A.,(2014). Estrategias de Marketing Sectorial, Madrid, España: ESIC. p.83

${ }_{12}$ Hoyos Ballesteros, R.,(2016). Branding El arte de marcar corazones. Bogotá, Colombia: ECOE ediciones. p. 168

${ }^{13}$ Moreno, H., (2014). La influencia del precio y las estrategias de comunicación visual basadas en simbología cultural sobre la preferencia de marcas ecológicas y consumo sostenible. EAN. (77), p. 173

${ }_{14}^{14}$ Cubillo, J., Blanco, A.,(2014). Estrategias de Marketing Sectorial. Madrid, España: ESIC. p.74

${ }^{15}$ Borin, N., Lindsey-Mullikin, J., \& Krishnan, R. (2013). An analysis of consumer reactions to green strategies. Journal of Product \& Brand Management, 22(2), p. 120.DOI 10.1108/10610421311320997. Recuperado el 12 de Abril de 2019. https://www.academia.edu/26519893/An_analysis_of_consumer_reactions_to_green_strategies
} 
estrategias de marketing ecológico, la primera se trata de productos verdes refiriéndose a la elaboración y desarrollo de nuevos productos bajo un patrón ecológico y sustentable. La segunda, abarca los productos reciclados, es decir productos ya existentes, siendo reciclados y transformados en productos sostenibles. Finalmente, la tercera propuesta se refiere a productos fabricados a través de procesos verdes, tratándose de productos confeccionados bajo procesos sustentables a lo largo de toda su cadena de producción, y cuya elaboración no afecta el medioambiente de manera considerable.

\subsection{METODOLOGIA}

La delimitación temporal aplicada en esta tesis es actual y la delimitación geográfica se centra en el ámbito internacional, específicamente sobre la mirada de las multinacionales con marcas sustentables, mediante la implementación de estrategias transculturales en diferentes mercados destinos.

La recolección de datos será cualitativa, mediante la interpretación de las fuentes primarias y secundarias. A través, de estas herramientas se elaborarán una serie de capítulos para profundizar conocimientos en marcas transculturales, sustentabilidad y estrategias utilizadas por las multinacionales.

Para realizar esta tesis de carácter exploratorio, se utilizarán fuentes primarias como vía para obtener información de parte de expertos y profesores especialistas. Por otra parte, las fuentes secundarias serán obtenidas desde libros académicos, sitios web de revistas científicas, que aborden los temas principales de este estudio. 


\section{CAPÍTULO II CARACTERÍSTICAS DE LA TRANSCULTURALIDAD DE LA MARCA}

El capítulo II se presenta el concepto básico de la globalización como el fenómeno que ha permitido agilizar el flujo de transacciones comerciales y de la comunicación. Asimismo, se describen los principales indicadores culturales necesarios para establecer estrategias transculturales aplicadas por las empresas internacionales.

\subsection{GLOBALIZACIÓN}

De acuerdo a Fitoussi y Rosanvallon $\left(1996: 119\right.$ - 122) ${ }^{16}$ la globalización surgió por medio de tres etapas históricas: la primera involucra la disminución gradual de los aranceles, que permitió aumentar las transacciones entre los países; la segunda se debió a la posibilidad de transferir flujos financieros vía electrónica (desarrollo de la informática y las telecomunicaciones); y la tercera contempla el colapso de la Unión Soviética, que se disgregó en doce países que posteriormente se integraron al comercio mundial. Por su parte, Bradley (2006:24) ${ }^{17}$ define la globalización como el desarrollo de la tecnología y la gestión del libre comercio, que promovieron la comunicación global integrada, las transacciones bancarias, el comercio y la fabricación mundial.

Fanjul en su artículo publicado a través del portal de $\mid$ |berglobal ${ }^{18}$, define la globalización como "La creciente interrelación en general entre los países del mundo", haciendo alusión a la transferencia de personas, objetos y servicios que influyen en la cultura local de cada nación. Otras acciones que intervienen en la cultura a nivel mundial son el desplazamiento de estudiantes internacionales, la mano de obra (extranjera) y diversas manifestaciones de actividades humanas. A su vez, hace mención del vínculo existente entre la globalización y las cadenas globales de valor definiéndolo como la fragmentación de actividades productivas, de distribución y comercial en diversos países, generando una ventaja competitiva (reducción de costos).

Tomassini (1996:318) ${ }^{19}$ define la globalización como "un conjunto de transformaciones que afecta a la sociedad, la economía, la política, los núcleos urbanos, la empresa, la oficina, el hogar y la utilización del tiempo libre". En este contexto se hace referencia al

\footnotetext{
${ }^{16}$ Fitoussi, J.; Rosanvallon, P., (1996). La nueva era de las desigualdades. Buenos Aires: Argentina, Ediciones Manantial. p.119- 122.

17 Bradley, F.; Calderon, H., (2006). Marketing Internacional, Pearson Prentice Hall, p. 24

${ }^{18}$ Fanjul, E., Iberglobal portal. Qué es la globalización. Recuperado el 10 de Mayo de 2019.

http://iberglobal.com/index.php/escuela-de-comercio-exterior/1559-que-es-la-globalizacion

19 Tomassini, L., (1996) El proceso de globalización y sus impactos socio-políticos. Estudios Internacionales, 29(115), p.

318. https://revistaei.uchile.cl/index.php/REl/article/view/15051/29141
} 
impacto no solo económico sino también político y social, productos de intercambios y transformaciones entre los diferentes actores de la sociedad internacional que conllevan a un debilitamiento de paradigmas históricos y culturales de cada nación, es decir, la globalización es un fenómeno de carácter multidimensional que atañe a los estados, agentes sociales y económicos.

Tomando en cuenta lo antes expuesto y considerando todas las definiciones como complementarias, se puede concretar que la globalización es un fenómeno y un proceso que incentiva la competitividad comercial, el desarrollo económico entre países y bloques económicos. Además, fomenta la especialización de actividades productivas, personales y comerciales e indirectamente interviene en las actividades humanas y sociales. Por lo tanto, la globalización influye de forma positiva y negativa en las estructuras culturales y económicas de las naciones a nivel internacional. A continuación, se hace mención de los aspectos positivos y negativos de la globalización:

\section{POSITIVOS}

- Fomenta el flujo financiero de las naciones a través de la Inversión Directa Extranjera.

- Favorece el desarrollo de las telecomunicaciones, permitiendo la realización de transacciones financieras más fácilmente. Del mismo modo, brinda la posibilidad a los individuos de estar interconectados desde cualquier lugar del mundo. Proporcionan beneficios laborales para los empleados como la posibilidad de trabajar desde casa o cualquier lugar disponible.

- Se incrementó el número de estudiantes que se trasladan a otros países.

- Se relaciona estrechamente con la extensión cadena de valor fragmentada (instalaciones productivas y de distribución, localizadas en zonas geográficas)

- Favorece el desarrollo de las cadenas de suministros globales

- Incentiva la creación de acuerdos y tratados comerciales entre las naciones y los bloques económicos.

\section{NEGATIVOS}

- Incentiva la producción y el consumo de bienes y servicios, pero no trabaja en función de la gestión de desechos orgánicos o inorgánicos.

- Afecta la cultura, el arte, la moda, educación de cada nación.

- Promueve los paraísos fiscales 
- Permite la compra y venta de artículos bélicos

- Posibilita la obtención de datos para el crimen organizado, con ayuda de los avances tecnológicos y a redes sociales.

\subsection{ELEMENTOS DE LA CULTURA}

La cultura está constituida por una serie de comportamientos, creencias y valores a través de las cuales la sociedad se manifiesta (Bradley, 2006:92) ${ }^{20}$. De esta manera, la cultura interviene en las actividades de una sociedad, pudiendo observarse en el lenguaje verbal y corporal, en los símbolos, costumbres y tradiciones, entre otros; la percepción de estos elementos impacta directa o indirectamente en la decisión y comportamiento de compra de la demanda internacional. Por lo tanto, el consumo está estrechamente vinculado con la cultura de los mercados destinos.

En este sentido, resulta necesario conocer los elementos que conforman la cultura y cómo actúan en el comportamiento de los usuarios y consumidores potenciales. Hollensen (2011:234- 236) ${ }^{21}$ menciona 8 indicadores que intervienen en la percepción de los consumidores, estos se detallan a continuación:

- IDIOMA: se proyecta a través del lenguaje. El lenguaje es el sello de identidad y pertenencia de un pueblo, forma parte de las principales vías de comunicación e interacción entre individuos y la sociedad.

Existe un vínculo profundo entre la cultura y el idioma; tomando en cuenta que el idioma proporciona palabras, gestos, conceptos y dialectos o jergas a una nación, permitiendo a los individuos que conforman esa patria comunicarse y entenderse entre ellos. En este sentido, el idioma se convierte en una barrera fronteriza de comunicación y diferenciación, entre los individuos globales. El idioma se compone de dos indicadores:

- LENGUAJE VERBAL: es la capacidad de comunicación entre individuos de una sociedad, por medio del uso de palabras y modismos autóctonos del país o región geográfica. El lenguaje verbal consiste en la comunicación a través de las palabras que pueden provenir de forma oral o escrita. Las palabras pueden variar su connotación de país en país; complejizando la comunicación

\footnotetext{
${ }^{20}$ Bradley, F.; Calderon, H., (2006). Marketing Internacional, Pearson Prentice Hall, p.92

${ }^{21}$ Hollensen, S., (2011). Global Marketing: A decision-oriented approach. (5 th ed.). Harlow essex, England: Prentice Hall. p. $234-236$
} 
entre individuos de diferentes países o regiones geográficas. Un ejemplo de ello son los idiomas de las etiquetas de productos internacionales, como las del vino que varían el idioma expuesto en etiquetas según el mercado destino al cual se exporte.

- PARALENGUAJE (ECKMAN): es la capacidad de transmitir un mensaje haciendo énfasis al componente vocal y gestual de un discurso. Los indicadores que conforman el paralenguaje son: el rostro (ojos y boca); las manos; la corporalidad (cuello y posición del cuerpo en general); la proxémica (laboral, social, sentimental y con los objetos muebles; la paralingüística (silencios, reiteraciones o muletillas, la voz incluyendo el tono, volumen y la velocidad al expresarse).

El paralenguaje es un medio de comunicación crucial y vigoroso, para las relaciones interpersonales sociales, comerciales e imagen de la marca. En este contexto, las imágenes, frases, vallas, folletos publicitarios de bienes y servicios son elementos de que involucran el paralenguaje.

- MODALES: consiste en las normas de comportamiento que codifican y establecen la conducta humana; este proceder forman parte de la identidad de una nación o región geográfica. Asimismo, es un aspecto importante la toma de conciencia sobre las expresiones personales en el proceso de generar vínculos o establecer relaciones sociales y/o empresariales con individuos o grupos que provengan de otra cultura. En este sentido, se hace referencia a las publicidades donde se demuestran los buenos modales, un ejemplo de este indicador es que un caballero ayude a sentar a una dama en un restaurante siendo este el contexto, donde se promociona una botella de vino (esta acción es asociada al elemento cultural e impacta en la percepción de la marca).

- COSTUMBRES: responde a las tradiciones ancestrales transmitidas de una generación a otra; estas tradiciones se extrapolan a toda la población local. Se refiere a cómo se hacen las cosas y como ésta se refleja en las actividades cotidianas de los ciudadanos locales. Un ejemplo visible de ello es la venta de las marcas comestibles internacionales que adicionan picantes a sus productos para adaptarse a las costumbres alimenticias mexicanas. Otro ejemplo es la venta de productos internacionales en Argentina adaptados con sabor a dulce de leche. 
- TECNOLOGÍA: los avances tecnológicos repercuten en el desarrollo social y cultural, interviniendo en los comportamientos, actitudes, pensamientos, valores y creencias de los individuos. A continuación, se describen los indicadores tecnológicos que influyen en la cultura:

- SOCIAL: la evolución de la tecnología ha permitido a los individuos reducir las barreras geográficas; brindando la posibilidad de estar interconectados, establecer relaciones personales o comerciales, romper paradigmas sociales, cambiar de perspectiva, entre otros. En este contexto, se menciona las marcas internacionales que por medio de la publicidad apoyan los ideales en contra del racismo, a favor de la inclusión, la igualdad de derechos, entre otros.

- PROFESIONAL: a nivel profesional la tecnología permite adquirir nuevos conocimientos, habilidades y destrezas en las áreas de interés de cada individuo. A su vez, es la principal herramienta de trabajo de los profesionales y empresas del mundo, proporcionando ventajas en el rendimiento, gestión y eficacia de cada individuo. En este sentido, se hace referencia las marcas computadoras que a través de la innovación y desarrollo de productos que facilitan la labor profesional de los diseñadores y arquitectos con sus equipos diseñados para obtener una mejor calidad en los gráficos y colores de los elementos diseñados.

- ECONOMÍA CULTURAL: la estructura económica en cada país o bloque económico influye en el comportamiento de la demanda y por ende afectan los factores de producción, intercambio, distribución y consumo de bienes y servicios. Asimismo, los convenios comerciales entre países y/o bloques económicos permiten fortalecer la estructura económica entre los estados involucrados, incrementando las plazas de trabajos y esto trae como consecuencia un aumento del consumo de bienes y servicios. Esto posibilita el consumo del arte, la literatura y el esparcimiento cultural, con el fin de proporcionar equidad en las actividades culturales para la sociedad. Un ejemplo de este indicador es la venta de productos que con su compra promocionan el acceso a conciertos, eventos teatrales, entre otros es un elemento económico cultural en la percepción de una marca. 
- INSTITUCIONES SOCIALES: se refiere a la relación entre los individuos de una comunidad con las instituciones que colaboran en la resolución de problemas sociales en la localidad. Estos organismos tienen la labor de satisfacer las necesidades fundamentales de la comunidad, trabajando en conjunto con otros organismos y asociaciones como instituciones educativas, económicas, políticas, de salud, religiosas y culturales. Los organismos pueden ser locales o internacionales dedicadas a proteger los derechos de la población, abogando especialmente por los sectores y grupos más desprotegidos (NSE bajo, diversidad de género, protección al medio ambiente, protección de género). En este sentido, se hace referencia a las imágenes de mujeres con cuerpos diferentes, individuos con rasgos físicos diversos, entre otros elementos expuesto en las publicidades como expresión de apoyo e integración cultural en la percepción de marca.

- EDUCACIÓN: está conformada por tres indicadores: el primero se sustenta en la formación académica de todo los miembros de la comunidad, con el fin de que se conviertan en individuos útiles para la sociedad; la segunda se refiere a la transmisión de las costumbres y tradiciones que pasa de generación en generación a través de la familia y las nuevas manifestaciones que se presentan en el entorno social; y por último la tercera corresponde a la transferencia de actividades especializadas, habilidades técnicas y desarrollo de ideas enfocadas a nivel laboral y crecimiento profesional.

Un ejemplo del primer indicador correspondiente a la educación hace referencia al apoyo que brindan las marcas transculturales a las comunidades más vulnerables, para que los niños que forman parte de ellas tengan acceso a la educación. Con respecto al segundo indicador educativo se relaciona con los mensajes expuesto en las publicidades de marcas que trascienden generaciones. Para finalizar, el tercer indicador se refiere a la publicidad a tecnologías para el desarrollo humano y dimensionadas al futuro (un automóvil más veloz, seguro y sin conductor) como un elemento cultural en la percepción de una marca.

- VALORES: corresponden a las características y principios que se consideran positivos ante la sociedad. Los valores establecen la diferencia entre lo que es correcto e incorrecto; basados en las creencias, conocimientos y tradiciones aprendidas. A continuación, se presentan los indicadores que influyen en los valores humanos: 
- RELIGIOSOS: las creencias religiosas influyen en la manera de pensar, expresarse y en el comportamiento de cada individuo. Asimismo, la religión posee un vínculo estrecho con los valores personales; especialmente en la conciencia sobre el bien, el mal y las acciones entre individuos. En este sentido, las publicidades o promociones de marcas transculturales en contra de la diversidad de género es un elemento cultural en la apreciación de marca.

- POLÍTICOS: los valores personales se ven influenciados por su cultura, tradiciones, educación y su entorno; permitiendo tener afinidad con los ideales de un sector político u otro. Un ejemplo de ello es la imagen de artistas reconocidos expuesto en publicidades con personalidades o elementos políticos, se convierte en un factor cultural en la percepción una marca transcultural.

- CULTURALES: la cultura establece una base sobre la cual los individuos adquieren conciencia por medio de la transferencia de conocimiento de generación a generación y por la transformación del entorno generacional. Este aspecto interviene en la concepción y creación de valores personales de cada individuo. En este contexto, la publicidad emitida por las grandes marcas en contra del consumo de drogas o cigarrillos bajo la expresión (DILE NO A LAS DROGAS) son aspectos que reflejan valores culturales positivos para la población en general.

- ACTITUDES: es la manifestación de los valores culturales expresada a través de conducta individualista o colectiva. Las actitudes forman parte de la identidad cultural de una comunidad, revelando la postura de los integrantes de la comunidad ante una situación particular o en el establecimiento de relaciones con miembros de otra sociedad. Un ejemplo, es la actitud que se expresa en las publicidades de las marcas transculturales mediante la composición de los rasgos gestuales, corporales, formas y colores en las publicidades a nivel global.

- ESTÉTICA: se relaciona con la interacción entre el hombre, el arte y la naturaleza. Aunado a ello, la estética vinculada a la cultura interviene en el proceso de realzar los siguientes aspectos: la música típica y el folklore cultural de una población, los conocimientos referentes al arte y la apreciación simbólica de las manifestaciones 
autóctonas de la comunidad. La estética permite que cada individuo reflexione sobre los conceptos referente a la belleza, armonía y autoexpresión. Un ejemplo: el arte expuesto en la publicidad es un elemento cultural en la percepción de una marca.

- RELIGIÓN: consiste en un conjunto de creencias, significados, interpretaciones grupales y convicciones referidas a una realidad suprema, trascendental a partir de las cuales los individuos pueden discernir sobre la ética, la moral y las buenas prácticas sociales. Este aspecto provee grandes diferencias entre las distintas religiones e influye directamente en las creencias, comportamientos, significados y percepciones de la población en general. Existen culturas en las que la religión tiende a ser el centro de las costumbres y comportamiento para toda la comunidad, es decir, las acciones de sus habitantes están estrechamente relacionadas con la normativa religiosa.

Del mismo modo, la religión participa en todas las sociedades; en unas de forma más activa mientras que en otras comunidades la participación es menos preponderante. La religión es una barrera transcultural y de consumo. Un ejemplo de ello, son las adaptaciones que sufren las publicidades occidentales que tienen como imagen a mujeres con atuendos provocativos, las cuales pasan por un proceso para cubrir los cuerpos de las damas con prendas de vestir para exponer la publicidad en del medio oriente.

\subsection{ESTRATEGIAS DE MARKETING TRANSCULTURAL}

Las estrategias de marketing transcultural consisten en la integración de variables culturales al plan de marketing a través de la promoción y difusión de bienes y servicios (Cubillo, 2014:33-34) ${ }^{22}$. El objetivo del marketing transcultural se basa en diseñar estrategias dirigidas a grupos insatisfechos por la falta del contexto cultural en los bienes y servicios ofertados por las empresas internacionales. Esto requiere incorporar en el plan de marketing los indicadores culturales que permitan a las empresas internacionales crear vínculos con los usuarios y en un futuro, disminuir los costos por transacción.

Marketing Transcultural se dedica a la investigación, análisis y al desarrollo de estrategias comerciales para que las empresas puedan acceder a mercados internacionales, trascendiendo las barreras culturales, conformadas por los valores nacionales y

${ }^{22}$ Cubillo, J., Blanco, A.,(2014), Estrategias de Marketing Sectorial, Madrid, España: ESIC.p. 33-34 
matriciales que con los cuales se identifica la demanda. Por su parte, Christiansen $(2013: 319-320)^{23}$ indica que expertos definieron el marketing transcultural como marketing de la diversidad o marketing multicultural, enfocando sus actividades en la diversidad cultural de los mercados destinos, la influencia de las características culturales en la elección de compra y el comportamiento de los consumidores.

Desde inicios del siglo XXI, los avances de la tecnología han permitido la conexión e interacción de los usuarios y grupos a través de las redes sociales. El análisis de estos medios otorga insight a los profesionales en marketing sobre los temas de importancia para la sociedad, que buscan ser satisfechos (Cubillo, 2014:69) ${ }^{24}$. Sin embargo, las empresas que buscan expandirse o globalizarse, se ven afectadas por las condiciones locales, estas diferencias son las que establecerán en qué medida se adaptarán las estrategias de marketing transcultural según los resultados locales de cada mercado destino (Llopis, 2015:179) ${ }^{25}$.

Las estrategias deben estar destinadas a satisfacer a la demanda, involucrando los siguientes indicadores en el desarrollo del plan de marketing transcultural (Bradley, 2006:92 $)^{26}$

- OFERTA DE LA EMPRESA VS LA COMPETENCIA: inicialmente corresponde realizar un análisis del mercado de oferta que involucre el mix de capacidades de la empresa vs la competencia, siendo el objetivo principal de la empresa beneficiarse de las debilidades de los competidores y pueda arrebatarles clientes (Bradley, 2006:75) ${ }^{27}$. Al mismo tiempo, la empresa intenta eliminar sus debilidades y mantener su participación en el mercado destino. Para ello, es necesario crear valor añadido a través de los siguientes pasos:

- Escuchar las necesidades de los consumidores

- Realizar uso eficaz de los recursos

- El desarrollo e innovación de productos

- Mantener una relación estrecha con los proveedores en busca de encontrar vías más efectivas para todo el proceso de distribución.

\footnotetext{
${ }^{23}$ Christiansen, B.,(2013). Transcultural Marketing for Incremental and Radical Innovation. Estados Unidos de America. Business Sciences References (and imprint by IGI Global). p. 319-320

${ }^{24}$ Cubillo, J., Blanco, A.,(2014), Estrategias de Marketing Sectorial, Madrid, España: ESIC.p. 69

${ }^{25}$ Llopis Sancho, E.,(2015). Crear la Marca Global Modelo: práctico de creación e internacionalización de Marca. Madrid, España. ESIC, p. 179

${ }^{26}$ Bradley, F.; Calderon, H., (2006). Marketing Internacional, Pearson Prentice Hall, p.92

${ }^{27}$ Bradley, F.; Calderon, H., (2006). Marketing Internacional, Pearson Prentice Hall, p.75
} 
- DESARROLLO DE PRODUCTOS: por lo general los productos de consumo internacional se introducen secuencialmente de mercado en mercado o de región a región, es decir, que en varios países se encuentran los mismo productos o servicios con adaptaciones culturales dirigidas a sus consumidores locales (Bradley, 2006:199 $)^{28}$. Esto es visible en los bienes y servicios de empresas multinacionales que operan en países desarrollados y al mismo tiempo llevan operaciones a países en vías de desarrollo.

Las empresas invierten un gran número de recursos y experiencia técnica necesarias para la investigación y el desarrollo de productos que buscan cubrir las necesidades de la demanda internacional. Actualmente, existen muchas joint ventures que permiten asumir los compromisos de desarrollar bienes y servicios con suministros acordes a los materiales requeridos para su fabricación, demostrando la complejidad industrial y la importancia de mantener buenas relaciones en el sistema productivo.

- INNOVAR PRODUCTOS Y SERVICIOS: las empresas que poseen operaciones comerciales en varios mercados internacionales requieren que sus productos y servicios tenga una diferenciación real e innovación auténtica que satisfagan las necesidades de la demanda y ofrezca un valor superior a los de los competidores (Bradley, 2006:173) ${ }^{29}$. Para conocer las necesidades de la demanda requiere ser diligentes en la investigación de mercados (de demanda y oferta), la generación de ideas y conceptos, identificar oportunidades; tomando en cuenta que cada mercado destino posee sus diferencias culturales.

Innovar requiere establecer nuevas características o agregar un surtido de producto mediante el uso de nuevas tecnologías, analizando el desarrollo de los sistemas a implementar además del impacto de los nuevos procesos en la demanda, el ambiente y la cultura de cada mercado destino. En mercados maduros la innovación es esencial para la supervivencia de la compañía, mediante la extensión de productos y servicios. A su vez, es posible innovar a través del diseño pudiendo transformar los productos estándar en productos de consumo popular y más atractivos dándole un refresh.

\footnotetext{
${ }^{28}$ Bradley, F.; Calderon, H., (2006). Marketing Internacional, Pearson Prentice Hall, p.199

${ }^{29}$ Bradley, F.; Calderon, H., (2006). Marketing Internacional, Pearson Prentice Hall, p.117-118
} 
- ANÁLISIS DAFO: permite tener una visión amplia del entorno exterior e interior de la empresa internacional. Realizando este análisis se podrá encarar y minimizar aquellos puntos en los que la compañía carece de aptitudes para alcanzar los objetivos planteados y establecer las estrategias comerciales para cada mercado destino (Cubillo, 2014: 117-118) ${ }^{30}$. Del mismo modo, se busca utilizar las ventajas competitivas para reforzar las estrategias de marketing transcultural.

El análisis DAFO de empresas multinacionales, incorpora variables culturales en cada indicador, poniendo de manifiesto la filosofía empresarial unificando las diferentes acciones corporativas. Los indicadores culturales complementan las capacidades, recursos y características físicas de la empresa brindándole mayor robustez al estudio de la situación actual de la empresa multinacional. De acuerdo con Llopis (2015:133 136) ${ }^{31}$ la construcción de la estrategia transcultural considera el análisis DAFO como una información complementaria para la toma de decisiones. A continuación, se presentan los indicadores que la componen:

- FORTALEZAS: características internas de la empresa que establecen ventajas competitivas, involucrando las capacidades, recursos y la posición en el mercado. Las fortalezas están compuestas con indicadores que demuestren que actividades son realmente buenas para la empresa internacional vs su competencia. Los puntos de semejanza con la competencia permiten tener una visión macro respecto se deben qué áreas o actividades a mejorar.

- DEBILIDADES: consiste en las capacidades que presumen ser una desventaja frente a la competencia. Para ello, se debe ser autocrítico con las debilidades que posea la empresa, considerando que cada indicador que represente una desventaja se puede transformar en una oportunidad. Las debilidades deben ser controladas y superadas mediante acciones tomadas por la empresa.

- OPORTUNIDADES: representan la posibilidad de mejora para las empresas internacionales por medio de manifestaciones del entorno externo. Consiste en tendencias o realidades de los mercados destinos que permiten beneficiar a empresas internacionales.

\footnotetext{
${ }^{30}$ Cubillo, J., Blanco, A.,(2014), Estrategias de Marketing Sectorial, Madrid, España: ESIC.p. 117-118

${ }^{31}$ Llopis Sancho, E.,(2015). Crear la Marca Global Modelo: práctico de creación e internacionalización de Marca. Madrid, España. ESIC, p. 133-136
} 
- AMENAZAS: son elementos externos que pueden afectar directamente las actividades de la empresa, de no ser afrontados representaría un riesgo importante para la empresa.

Las estrategias transculturales deben de estar alineadas con la cultura corporativa que proporcione una dirección clara para la toma de decisiones futuras. Esta coherencia entre la filosofía empresarial y las acciones corporativas aumenta la confianza de los consumidores, afianzando la creación de vínculos emocionales entre las partes. Las empresas internacionales buscan fidelizar a sus consumidores y usuarios, para ello no solo identifican sus insatisfacciones y deseos, sino que a su vez buscan conquistar las

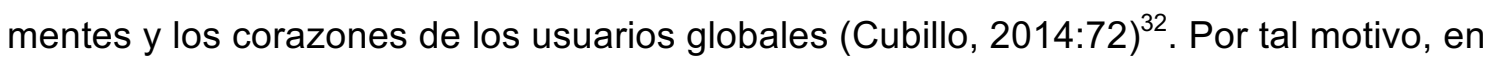
entornos internacionales las empresas deben considerar los siguientes aspectos en el diseño de las estrategias transculturales:

- MISIÓN: es la declaración que manifiesta el negocio en el que opera la empresa. Es una sentencia breve que comunica de manera sintetizada los beneficios y soluciones de necesidades de los consumidores que se relacionan con la actividad de la organización. (Cubillo, 2014:73) $)^{33}$

- VISIÓN: establece el deseo de la empresa, hace referencia a donde se proyecta la organización. Sugiere a que aspira convertirse la empresa en un futuro mediante un enunciado. La visión engloba el objetivo final que la empresa internacional busca alcanzar estimulando a todos los colaboradores a trabajar alineados en pro de este futuro deseable. Llopis $(2015: 163)^{34}$.

- VALORES: son un conjunto de principios y decálogos éticos que establecen los pilares de conducta de los colaboradores de la empresa a nivel profesional y relacional. Los valores deben constar por escrito y ser distribuidos a los empleados durante su ingreso a la empresa. Llopis $(2015: 163)^{35}$.

\footnotetext{
${ }^{32}$ Cubillo, J., Blanco, A.,(2014), Estrategias de Marketing Sectorial, Madrid, España: ESIC.p. 72

${ }^{33}$ Cubillo, J., Blanco, A.,(2014), Estrategias de Marketing Sectorial, Madrid, España: ESIC.p. 73

${ }^{34}$ Llopis Sancho, E.,(2015). Crear la Marca Global Modelo: práctico de creación e internacionalización de Marca. Madrid, España. ESIC, p. 163

${ }^{35}$ Llopis Sancho, E.,(2015). Crear la Marca Global Modelo: práctico de creación e internacionalización de Marca. Madrid, España. ESIC, p. 133-136
} 
- ESTRATEGIAS Y TÁCTICAS: Las estrategias de marketing transcultural consisten en el conjunto integrado de providencias de recursos corporativos dedicados a optimizar la rentabilidad empresarial a largo plazo. A través de las estrategias las empresas internacionales buscan penetrar las barreras culturales del mercado destino, adaptando la estructura de negocio con el propósito de generar mayor valor agregado y ventajas competitivas sostenibles. (Bradley, 2006:6) (36 $^{36}$

Marketing táctico complementa las estrategias tomadas en el plan de marketing estratégico transcultural. Las acciones tácticas son moldeables al entorno del momento en el que se aplican y ejecutadas a corto plazo. Un aspecto importante para tener en cuenta, antes de efectuar una acción táctica es tener conocimiento del entorno externo e interno que permita analizas y explorar la mejor opción a implementar en circunstancias complejas (Cubillo, 2014:59) ${ }^{37}$.

\subsection{MARCA TRANSCULTURAL}

La marca proviene de un antiguo vocablo escandinavo: brand, que significaba quemar, refiriéndose al modo en que el hombre marcaba sus reses (Hoyos, 2016:13) ${ }^{38}$. "La marca es un nombre, símbolo o diseño, o una combinación de ellos, cuyo propósito es designar los bienes o servicios de un fabricante o grupo de fabricantes, y diferenciarlos del resto de los productos y servicios de otros competidores" (Kotler, 2001: 404) ${ }^{39}$. Actualmente se conoce que la marca es un elemento complejo que se ve influenciado por la percepción cultural de la demanda en los distintos países donde se comercializan sus productos. (Cepeda, 2014:136) ${ }^{40}$

Una marca transcultural debe transmitir una identidad clara y ser aspiracional, alcanzando una diferenciación que la destaque frente a su competencia por medio de la creación de conexiones racionales y emocionales que generara fuertes vínculos con sus consumidores (Bernabel, 2015:18-19) ${ }^{41}$. Por ello, es necesario conocer qué percepciones

\footnotetext{
${ }^{36}$ Bradley, F.; Calderon, H., (2006). Marketing Internacional, Pearson Prentice Hall, p.6

${ }^{37}$ Cubillo, J., Blanco, A.,(2014), Estrategias de Marketing Sectorial, Madrid, España: ESIC.p. 59

${ }^{38}$ Hoyos Ballesteros, R.,(2016). Branding El arte de marcar corazones. Bogotá, Colombia: ECOE ediciones. p. 13

${ }^{39}$ Kotler, Philip (2001). Dirección De Marketing. Distrito Federal, México: Editorial Prentice Hall.

${ }^{40}$ Cepeda-Palacio, S.,(2014), Alcances actuales del concepto de marca. Un estudio comparativo, en la historia.

Entramado,10(2), p.136

${ }^{41}$ Bernabel, A.,(2015). Identidad y deterioro de imagen de la marca, caso: Calzado deportivos Kelme.Comuni@cción, 7 (1).

p. 18-19. https://www.redalyc.org/pdf/310/31045569006.pdf
} 
y valores evoca la marca transcultural a los usuarios de cada país destino, tomando en cuenta que es un elemento determinante de la supervivencia de la empresa en el mercado destino.

El desafío de los profesionales del marketing es identificar cómo deben transmitirse los valores compartidos entre la cultura de cada mercado destino y la identidad de marca, siendo la cultura quién posiciona y diferencia una marca transcultural (Llopis, 2015:139$141)^{42}$. Es decir, que cuando un individuo lleva consigo un elemento con la marca transcultural, las cualidades de la marca se extrapolan al usuario y se comunican a la sociedad (Jiménez y Camirra, 2015:184 -185) ${ }^{43}$.En este sentido, la marca transcultural se transforma en un elemento de comunicación y autoexpresión en un entorno social.

Actualmente el consumo es considerado como un elemento de autoexpresión social y cultural que es utilizado por los usuarios para identificarse, distinguirse y diferenciarse de

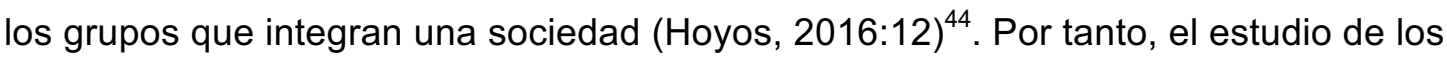
elementos que estimulan la adquisición de una marca transcultural es un aspecto fundamental dentro del análisis del marketing. Dicha investigación debe involucrar a los potenciales usuarios, considerando que todos en alguna oportunidad pasada o futura, han sido o serán consumidores.

La investigación cultural permite identificar puntos de interés, los valores propios de un mercado destino y su situación competitiva. Este estudio se dedica a la recopilación e interpretación de datos, los cuales son obtenidos a través de discusiones de grupos focales, observaciones etnográficas, análisis semiótico de significados de palabras e imágenes y entrevista en profundidad, permitiendo combinar información cuanti y cualitativa que proporcionen una orientación para la toma de decisiones, acciones y estrategias para las empresas internacionales (Tharp, 2014:88) ${ }^{45}$. Cada cultura tiene sus características, el reto que enfrentan las marcas transculturales es determinar qué vínculos culturales transmitirá la identidad de su marca con la del país destino.

En conclusión, las características culturales de la demanda internacional intervienen en la selección y adquisición de bienes. Es por ello, que las estrategias marketing internacional

\footnotetext{
${ }^{42}$ Llopis Sancho, E.,(2015). Crear la Marca Global Modelo: práctico de creación e internacionalización de Marca. Madrid, España: ESIC, p. 139-141

${ }^{43}$ Jiménez, A; Camirra, H., (2015). Nuevas tendencias del mercadeo internacional: enfoque del branding y su vinculación con el consumidor. Economía. XL (40), p.184 - 185

${ }^{44}$ Hoyos Ballesteros, R.,(2016). Branding El arte de marcar corazones. Bogotá, Colombia: ECOE ediciones. p. 13

${ }^{45}$ Tharp, M., (2014). Transcultural Marketing. New York, Estados Unidos: Taylor and Francis Group, p. 88
} 
toman en cuenta las cualidades culturales de cada mercado destino con el propósito de adaptar la oferta de la empresa para satisfacer los deseos y necesidades la demanda internacional. Del mismo modo, la cultura influye en la apreciación alegórica de marca requiriendo ajustar su imagen tanto empresarial como de marca en aquellos mercados destinos que lo requieran. Para ello, las marcas internacionales acondicionan su imagen y en algunos casos sus nombres de acuerdo con los valores compartidos con la demanda del mercado destino. 


\section{CAPÍTULO III SUSTENTABILIDAD EN LAS MARCAS DE PRODUCTOS INTERNACIONALES}

El capítulo III aborda las características sustentables de las marcas internacionales. Este capítulo detalla las cualidades que presenta la demanda relacionadas a la compra, uso y acciones de artículos sustentables ofertados por marcas internacionales. Estos argumentos sirven de apoyo para la aplicación de estrategias de marcas internacionales orientadas a generar valor y rentabilidad a las empresas.

\subsection{CARACTERÍSTICAS DE LAS MARCAS SUSTENTABLES}

Las características de las marcas sustentables se basan en un modelo de gestión macro fundamentado en la protección medioambiental, es decir, contempla desde la extracción de la materia prima para la fabricación, los procesos productivos, la distribución, su consumo y la eliminación de los desechos después de su vida útil (Sarkar, 2012:41) ${ }^{46}$. A su vez, las marcas sustentables involucran en sus actividades empresariales criterios e indicadores que preserven el medioambiente, el bienestar económico, humano y social evitando comprometer el equilibrio ecológico y el futuro de próximas generaciones.

Hoy en día la preocupación de los científicos, de la población mundial y de las ONG por los problemas ambientales, han impulsado la creación e implementación de normativas empresariales internacionales, nacionales y locales que fomenten los procesos ambientalmente seguros. Las marcas ecofriendly realizan mejoras en sus cadenas de valor con el objetivo de cuidar los estándares de calidad, velar por los incentivos económicos de las empresas y preservar el entorno ambiental.

Los productos ambientalmente seguros generan valor al mercado de demanda quienes aprecian la actuación ecológica, potenciando el ingreso de nuevos clientes en el futuro (Cubillo y Blanco, 2014:79-78) ${ }^{47}$. De acuerdo con Sarkar (2012:41) $)^{48}$ las marcas para ser consideradas sustentables no deben contribuir con los siguientes indicadores:

\footnotetext{
${ }^{46}$ Sarkar, A., (2012). Green Branding and eco-innovations for evolving a sustainable green marketing strategy. Asia-Pacific Journal of Management Research and Innovation. 8(1), p. 41. DOI: 10.1177/2319510X1200800106. Recuperado 21 de Enero de 2019.https://www.academia.edu/9238214/Green Branding and Eco-

innovations for Evolving a Sustainable Green Marketing Strategy Innovation Additional services and information for ${ }^{47}$ Sarkar, A., (2014), Estrategias de Marketing Sectorial, Madrid, España: ESIC.p. 79-78

${ }^{48}$ Sarkar, A., (2012). Green Branding and eco-innovations for evolving a sustainable green marketing strategy. Asia-Pacific Journal of Management Research and Innovation. 8(1), p. 41. DOI: 10.1177/2319510X1200800106. Recuperado 21 de Enero de 2019.https://www.academia.edu/9238214/Green_Branding_and_Eco-

innovations_for_Evolving_a_Sustainable_Green_Marketing_Strategy_Innovation_Additional_services_and_information_for
} 
- ATENTAR CONTRA LA SALUD DE LOS CONSUMIDORES O DE LOS ANIMALES: se refiere a la fabricación de productos que contengan elementos que resulten dañinos para los seres humanos y/o animales. Esto involucra los artículos para limpieza del hogar, productos industriales, personales y alimenticios, que contengan sustancias y/o compuestos químicos, pesticidas, conservantes y hormonas. Algunas de estas sustancias se pueden encontrar en frutas y verduras infectadas con pesticidas que son ingeridos por los consumidores.

La marca multinacional de té Lipton realiza esfuerzos para abastecer mundialmente a todos sus clientes y consumidores con bolsas de té, provenientes de cosechas sustentables. Para ello, Lipton ha establecido alianzas con la organización independiente Rainforets quienes trabajan en conjunto con la empresa con el objetivo de capacitar sobre metodologías de cultivo a los agricultores de acuerdo con criterios ambientales, sociales y económicos que favorezcan a todos los integrantes del circuito productivo.

- DAÑo Al MEdiO AMBIENTE (DURANTE SU CICLO DE VIDA, DE INICIO A FIN): este indicador contempla de inicio a fin los procesos realizados por las empresas para la fabricación de sus productos. Por lo tanto, se consideran como acciones que atentan contra el medio ambiente:

- La extracción y explotación de arena y grava, aceite de palma, madera, de la ganadería, de materia prima de origen mineral, entre otros.

- Los procesos de pretratamiento o de fabricación que involucren productos químicos o contaminantes

- La generación de residuos no biodegradables

- La eliminación de desechos después de cumplir su función.

Un ejemplo opuesto a este indicador es la marca Dove, específicamente su línea de antitranspirantes comprimidos que utiliza el $50 \%$ menos de gases propelentes y $30 \%$ menos de aluminio por envase, mediante la integración en su sistema productivo de una nueva tecnología. (1) ${ }^{49}$

\footnotetext{
${ }^{49}$ Recuperado de ---
} 
- DAÑOS Y DESPERDICIOS INNECESARIOS: consisten en el excesivo uso de materiales utilizados en el envasado y embalaje; la producción desproporcionada de artículos, producto de vida útil corta; la generación de desperdicios de materiales de forma abundante durante la producción; y el sobre procesamiento. En estas acciones se observan a lo largo de la cadena de suministro de diversos productos y todos los rubros, sin embargo, es más notorio en las verduras y vegetales que ofrecen los supermercados (Walmart, Carrefour, entre otros) que tienden a embalar estos productos con una bandeja de plástico y papel film.

- USO DESPROPORCIONADO DE LOS RECURSOS: se refiere al consumo de energía y recursos naturales de manera inconsciente, como la instauración de actividades agropecuarias intensivas y la implementación de una larga cadena de distribución que forman parte de las prácticas que afectan directamente al medio ambiente.

La evaluación de actividades realizadas por las empresas permitirá adaptar y optimizar los procesos, establecer mejoras en la cadena de suministros y encontrar alternativas para el uso eficiente de los recursos. Para ello, se requiere generar sinergias en toda la cadena de valor con el propósito de lograr un modelo sustentable.

L'Oréal es una empresa que ha trabajado en los últimos años en la reducción de emisiones de dióxido de carbono a un $50 \%$ en la elaboración de sus productos, con el objetivo de desarrollar e innovar en las áreas de productos y envase de artículos más responsables con el medio ambiente, entre otras iniciativas. ${ }^{50}$

- CRUELDAD O USO INNECESARIO CONTRA LOS ANIMALES: este indicador se relaciona al maltrato, violencia, abuso, tortura, no suministrar alimento, y cualquier acto, acción u omisión que causen sufrimiento o dolor innecesario a los animales. El uso de animales en pruebas científicas, experimentos con la finalidad cosmética y de limpieza, con fines económicos (comercio de mascotas exóticas, caza de animales, cría de mascotas para su comercialización, peleas de animales). También aplica a las condiciones en las que se transportan los animales de un lugar a otro de manera inapropiada, la conducta y procedimientos inadecuados aplicados a los animales en los mataderos.

\footnotetext{
${ }^{50}$ Recuperado de ----
} 
PETA es la organización de protección de animales más grande del mundo, esta organización tras un riguroso proceso de verificación añade a su lista de marcas libre de crueldad, a la empresa global Procter \& Gambel a través de su línea de shampoo Herbal Essences, que promueve la innovación y el desarrollo de tecnologías para sus productos, sin realizar pruebas en animales. ${ }^{51}$

- USO DE ESPECIES O AMBIENTES AMENAZADOS: se refiere a la utilización de especies de origen animal o vegetal con riesgo de extinción en la elaboración de bienes, también aplica la caza o cualquier actividad de comercialización que involucren especies en estas condiciones. Del mismo modo, este indicador incluye el uso de hábitats amenazados por las acciones del hombre y de las empresas como el uso de la flora y espacios naturales para la explotación minera, la producción agroindustrial y la deforestación.

En la actualidad un gran número de marcas internacionales han incorporado características sustentables en su cadena de valor y en su oferta comercial contribuyendo a reducir el impacto ambiental. La aplicación de los indicadores sustentables adaptados a las operaciones de cada empresa ofrecerá resultados útiles para mejorar los procesos y aumentar la competitividad organizacional por medio de una gestión más consciente con el medio ambiente (Zwerg, 2008:12) ${ }^{52}$. La comunicación de las cualidades sustentables reales de la marca internacional le permitirán establecer confianza y credibilidad entre los clientes y la marca internacional.

Figura 1

Modelo de características de marcas sustentables

\footnotetext{
${ }^{51}$ RECUPERADO DE

${ }^{52}$ Zwerg, A.,(2008), Incidences and Analyses of Green Marketing Strategy in Colombian Exports, 13, p.12. Recuperado el 12 de Mayo de 2019. http://www.redalyc.org/articulo.oa?id=322327243001
} 


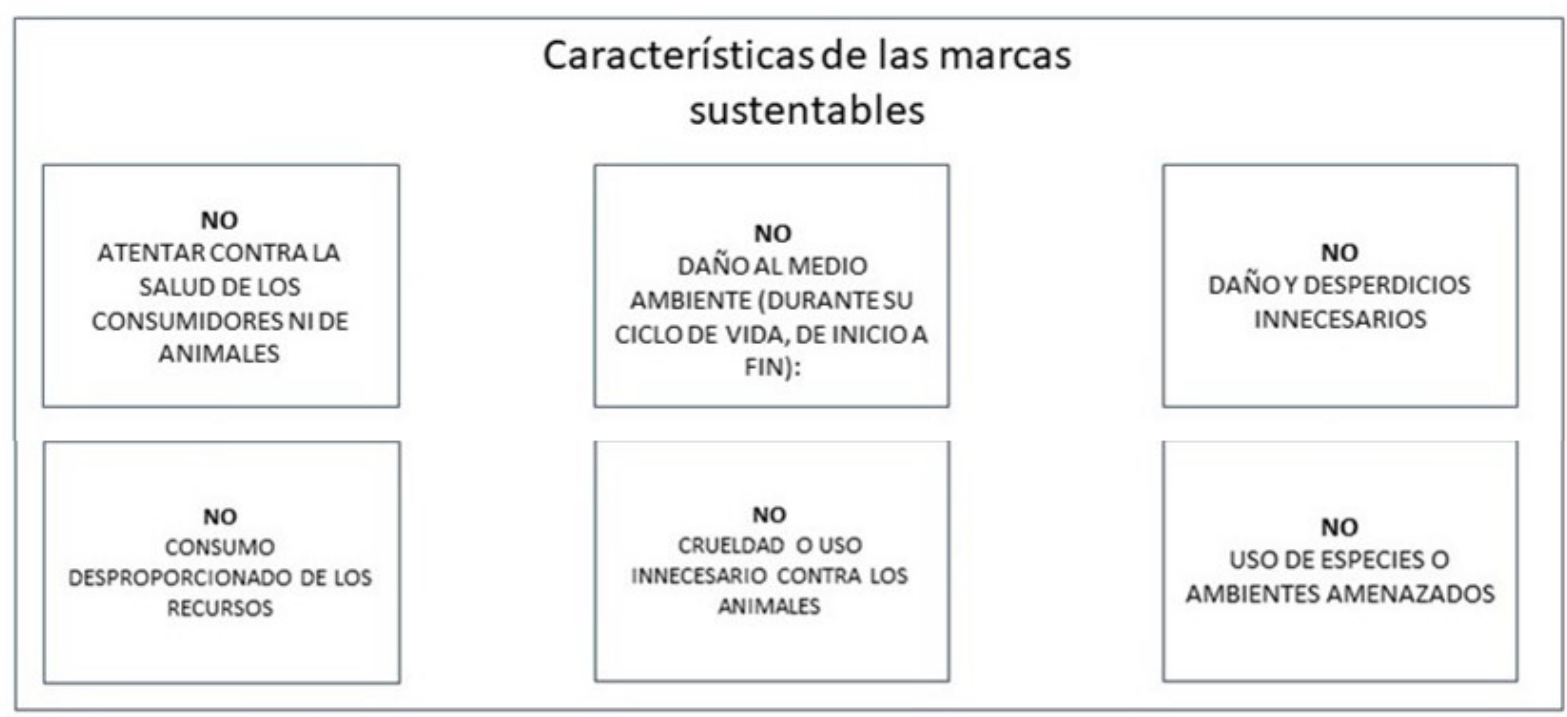

Fuente: Elaboración propia en base a los autores Sarkar( 2012) y Cubillo y Blanco (2014)

\subsection{CUALIDADES DEL MERCADO DE DEMANDA SUSTENTABLES}

La demanda sustentable está conformada por quienes compran, pagan, consumen y usan bienes de marcas internacionales que no atenten contra el medio ambiente, es decir, solo adquieren aquellos artículos que generen el menor impacto ambiental negativo, que no provengan de animales en extinción o que no hayan sido torturados durante todos los procesos de la cadena de suministro (Sarkar, 2012:42) ${ }^{53}$. Por lo tanto, son individuos que respetan y protegen el entorno ambiental y las especies que lo componen mediante acciones responsables con el medio ambiente.

De acuerdo con Cubillo y Blanco (2014:83-84) ${ }^{54}$ la demanda ecológica tiende a caracterizarse por su preocupación relacionadas al cuidado ambiental, el uso y consumo consciente de los recursos y el entorno socialmente responsable. Los clientes y consumidores sustentables son individuos informados sobre que marcas, bienes y servicios cumplen con las características y normativas que impulsa el desarrollo económico y social de las comunidades sin causar daño ecológico.

La demanda sustentable muestra una inclinación hacia la conciencia ecológica en la compra, uso y consumo de artículos que produzcan menos daño al entorno ambiental,

\footnotetext{
${ }^{53}$ Sarkar, A., (2012). Green Branding and eco-innovations for evolving a sustainable green marketing strategy. Asia-Pacific Journal of Management Research and Innovation. 8(1), p. 42. DOI: 10.1177/2319510X1200800106. Recuperado 21 de Enero de 2019.https://www.academia.edu/9238214/Green_Branding_and_Ecoinnovations for Evolving a Sustainable Green Marketing Strategy Innovation Additional services and information for ${ }^{54}$ Cubillo, J., Blanco, A.,(2014), Estrategias de Marketing Sectorial, Madrid, España: ESIC.p. 83-84
} 
además de realizar actividades de postventa que permitan ampliar el ciclo de vida de los productos y generar la menor cantidad de desechos posibles. A continuación, se detallan los comportamientos de la demanda sustentable:

- COMPORTAMIENTO DE COMPRA: se refiere a aquellos compradores o clientes que solo adquieren marcas y productos avalados por las entidades y organizaciones ecofriendly (quienes certifican la procedencia y el compromiso ambiental, social y económico con las comunidades que les proveen a las empresas internacionales la materia prima e insumos para le elaboración de sus artículos).

Estos individuos se caracterizan por estar constantemente informados sobre que empresas internacionales se incorporan a la iniciativa sustentable y aquellas que, por razones comerciales, económicos o éticas dejan de pertenecer al conjunto de entidades responsables con el medioambiente y la sociedad. A su vez, tienden a realizar sus compras en lugares orientados a la venta de productos ecológicos, artesanales o ferias orgánicas locales.

- COMPORTAMIENTO DE USO YIO CONSUMO: involucra a todos los usuarios y consumidores de artículos ecológicos que manifiesten acciones que preserven el medioambiente. Este apartado incluye los procesos de uso y la eliminación segura de desechos realizando actividades como las que se describen a continuación:

- Reciclar, restaurar y reutilizar productos con el propósito de maximizar el ciclo de vida reduciendo la generación de desechos innecesario.

- Utilizar y consumir recursos de forma eficiente.

- Separar los desechos para que puedan ser destinados por las empresas como material reciclable y apoyar la adecuada gestión de desperdicios.

- Consumir y/o utilizar bienes biodegradables u orgánicos.

- Reducir o eliminar la cantidad de desechos innecesarios

La demanda de productos sustentables aspira que los artículos cumplan con su funcionalidad y los niveles de calidad para lo que son elaborados (Hoyos 2016:166$168)^{55}$. Sin embargo, se conoce que las decisiones de compra, uso y consumo están

\footnotetext{
${ }^{55}$ Hoyos Ballesteros, R.,(2016). Branding El arte de marcar corazones. Bogotá, Colombia: ECOE ediciones. p. 166-168
} 
estrechamente vinculados a la cultura, educación, legislación, variables sociodemográficas, psicológicas y el entorno social de los individuos (Llopis, 2015:140) ${ }^{56}$.

Por medio de los avances, los desarrollos tecnológicos, las ONG y grupos ambientalistas la demanda está informada sobre los problemas ecológicos. Esto ha impulsado que los individuos adquieran comportamientos más responsables con el ecosistema y tomen conciencia sobre cómo sus decisiones de compras afectan el medioambiente (Sarkar, 2012:42) ${ }^{57}$. Es por ello, que en la actualidad existe un incremento de la conciencia ecológica y la responsabilidad de las empresas e individuos en realizar actividades más respetuosas con el medio ambiente certificando los procesos y la materia prima que componen los productos.

\subsection{ESTRATEGIAS DE MARKETING SUSTENTABLE}

Las estrategias de marketing sustentable están orientadas a minimizar el impacto ambiental producido por la venta, consumo y el uso de productos, por lo que se analizan todas las fases productivas, tomando en cuenta los proveedores y los procesos de fabricación de la empresa con el fin de satisfacer las necesidades ecológicas y los deseos de la demanda internacional de trabajar por un mejor planeta. Este estudio también comprende el ciclo de vida de los productos, el uso de materiales sustentables, el flujo de recursos y la responsabilidad extendida de los productores, incorporando estos factores en la estructura estratégica de la empresa internacional (Sarkar, 2012:43) ${ }^{58}$.

En la actualidad un gran número de empresas multinacionales han adaptado sus procesos, artículos, promociones y empaques por un enfoque menos perjudicial para el medioambiente con el propósito de generar valor agregado al mercado de demanda. De acuerdo con Borin, Lindsey-Mullikin y Krishnan (2013:120) ${ }^{59}$ las estrategias de marketing sustentable se fundamentan en tres indicadores esenciales que son implementados de

\footnotetext{
${ }^{56}$ Llopis Sancho, E.,(2015). Crear la Marca Global Modelo: práctico de creación e internacionalización de Marca. Madrid, España: ESIC, p. 140

${ }^{57}$ Sarkar, A., (2012). Green Branding and eco-innovations for evolving a sustainable green marketing strategy. Asia-Pacific Journal of Management Research and Innovation. 8(1), p. 42. DOI: 10.1177/2319510X1200800106. Recuperado 21 de Enero de 2019.https://www.academia.edu/9238214/Green_Branding_and_Ecoinnovations for Evolving a Sustainable Green Marketing Strategy Innovation Additional services and information for ${ }_{58}^{5}$ Sarkar, A., (2012). Green Branding and eco-innovations for evolving a sustainable green marketing strategy. Asia-Pacific Journal of Management Research and Innovation. 8(1), p. 42. DOI: 10.1177/2319510X1200800106. Recuperado 21 de Enero de 2019.https://www.academia.edu/9238214/Green_Branding_and_Ecoinnovations_for_Evolving_a_Sustainable_Green_Marketing_Strategy_Innovation_Additional_services_and_information_for ${ }_{59}$ Borin, N., Lindsey-Mullikin, J., \& Krishnan, R. (2013). An analysis of consumer reactions to green strategies. Journal of Product \& Brand Management, 22(2), p. 119.DOI 10.1108/10610421311320997. Recuperado el 12 de Abril de 2019. https://www.academia.edu/26519893/An_analysis_of_consumer_reactions_to_green_strategies
} 
acuerdo con los objetivos y las capacidades de cada empresa. A continuación, se presentan los indicadores de las estrategias sustentables:

- NUEVOS PRODUCTOS ECOLOGICOS: se refiere al diseño y desarrollo de nuevas categorías o línea de productos que contaminen en menor medida el medioambiente. Estos artículos son confeccionados considerando el ciclo de vida del producto, los componentes, el envase y embalaje que no atenten contra los animales o espacios amenazados durante toda la cadena de suministro.

Un ejemplo de nuevos productos ecológicos es la marca internacional Amway con su categoría de productos para la limpieza, Home está diseñada para la limpieza del hogar y el cuidado de la ropa sin dañar al medioambiente. Esta categoría de producto cuenta con una extensa línea de artículos con cualidades sustentables y cuentan con la certificación de A.I.S.E (Asociación Internacional de Jabones, detergentes y Productos de Mantenimiento) dedicado a impulsar diversas iniciativas para la seguridad humanas y ambiental. Adicionalmente, Home forman parte del programa de Safer Choices de la EPA (Agencia de Protección del Medio Ambiente) que trabaja para identificar y asegurar el uso de componentes sustentables en la fabricación de productos. ${ }^{60}$

- PRODUCTOS RECICLADOS Y/O REFACCIONADOS: consisten en la elaboración de artículos utilizando como materia prima los componentes de productos en desuso y los desechos, ayudando a disminuir la cantidad de residuos y de insumos, reduciendo la contaminación de vertedero y minimizando la incineración de desperdicios. En la actualidad existe un interés por reciclar por parte de la industria en general, pudiendo observarse una amplia gama de productos reciclados en el marcado de oferta como artículos decorativos, cuadernos, carteras para damas y caballeros, entre otros.

La reutilización es el proceso de volver a utilizar de forma parcial o completa los componentes que finalizaron su ciclo de vida, para la fabricación de nuevos productos que cumplan la misma función para los que fueron creados o por el contrario sean destinadas a un nuevo oficio. Este indicador estimula la reducción de la producción de nuevos componentes y la fabricación de artículos de cero, aprovechando los bienes que han sido utilizados previamente. Este apartado involucra alimentos agropecuarios que utilizan las sobras y desperdicios de productos de esta categoría para la producción de abono que se empleará en el cultivo de nuevas plantaciones agropecuarias.

\footnotetext{
${ }^{60}$ RECUPERADO DE
} 
Apple presenta un programa para reciclar sus artículos en todo el mundo. En países desarrollados como Estados Unidos y España, entre otros; tienen una campaña en la que sus clientes pueden canjear los artículos de la empresa por una tarjeta de regalo con descuentos para la compra de un nuevo producto. En su sitio web oficial sus clientes pueden conocer un valor estimado con el descuento aplicado a cada producto Apple si se dona un artículo en desuso de la empresa. En países subdesarrollado como Argentina solo aplica el circuito de reciclaje sin acceso a la posibilidad de descuentos. ${ }^{61}$

Coca Cola Company está realizando cambios importantes en su cultura empresarial adaptando un modelo más consciente con el medio ambiente, entre sus diversas actividades sustentables se destaca el desarrollo de un único recipiente para toda su oferta de bebidas gaseosas de 2 litros (presentación retornable), con el objetivo de reutilizar de forma más eficientes los envases y reduciendo los esfuerzos al momento de recolectar las botellas (que anteriormente eran diferentes para cada línea de producto). De acuerdo con Coca Cola Company la nueva Botella Única se comercializa en envase de vidrio y plástico, esta última tiene la capacidad de ser reutilizadas 15 veces y su composición contiene menos PET, minimizando la generación de carbono. ${ }^{62}$

- PROCESOS SUSTENTABLES: Los procesos sustentables trabajan en función de los objetivos ecológicos planteados por las empresas considerando el bienestar social y económico de las comunidades. Esto involucra una serie de actividades a nivel industrial, comercial y de gestión que tomen en cuenta la protección y buenas prácticas en el uso de los recursos naturales, entre otras acciones como:

- El uso eficiente de energía

- Mejoras de los procesos productivos y de la cadena de suministro.

- Reducción o eliminación de desechos en la producción de artículos.

- Consumo responsable de recursos naturales (como por ejemplo emplear sistema de riego por goteo para actividades agropecuarias)

- Utilizar maquinarias que tengan un menor impacto ambiental.

- Extraer y Explotar los recursos de manera consiente, respetando los ecosistemas y sus integrantes.

\footnotetext{
${ }^{61}$ Recuperado de link

${ }^{62}$ Recuperado de link
} 
- Reducir las emisiones que afectan al medio ambiente producidas por los procesos productivos.

- Tratamiento de aguas residuales producidas por las fábricas e infraestructuras de las empresas.

- Trabajar junto a sus proveedores con el fin de obtener materia prima ecológicas y que promueva el desarrollo económico de sus aliados.

- Ofrecer condiciones salariales y laborales justas para sus colaboradores.

Grupo Bimbo apuesta por procesos y acciones sustentables, para ello todas sus instalaciones migran progresivamente al consumo de energías renovables, promueven la eliminación de desperdicios, redujeron el uso de agua (realizando tratamiento de aguas residuales) y adquirieron una flota de vehículos eléctricos para la distribución de su producto. A su vez, la empresa ha invertido en el desarrollo e innovación para disminuir el uso de plástico en todos sus procesos productivos y en la elaboración de sus empaques, sustituyendo el plástico por materiales biodegradables, reciclables y/o compostable que tengan un impacto positivo con el medio ambiente. ${ }^{63}$

Estos productos y procesos sustentables se dedican a preservar los recursos naturales, los ecosistemas y a cuidar la calidad de los artículos que ofertan a mercados de demanda con el objetivo de continuar generando rentabilidad a sus operaciones, bajo un esquema más responsable con el entorno social y el medioambiente. Diversas empresas internacionales de todos los rubros han empezado a transformar sus ofertas comerciales por una orientación más ecológica tomando en cuenta el creciente interés de la población mundial por problemas ambientales.

\subsection{MARCAS SUSTENTABLES}

La creciente preocupación de los científicos, gobiernos y la sociedad en general por el deterioro ecológico han promovido la integración de variables ambientalmente seguras en los procesos estratégicos, productivo y comerciales de las empresas (Cubillo y Blanco, 2014:77-81 $)^{64}$. De allí, surge la necesidad de establecer una gestión empresarial orientada al uso eficiente de los recursos, el análisis y transformación de los procesos que causan daño al medio ambiente migrando a operaciones sustentables y la incorporación de actividades de reciclaje en las operaciones.

\footnotetext{
${ }^{63}$ REFERENCIA

${ }^{64}$ Cubillo, J., Blanco, A.,(2014), Estrategias de Marketing Sectorial, Madrid, España: ESIC.p. 89-90
} 
Según (Sarkar, 2012:43) ${ }^{65}$ una marca sustentable comercializa productos seguros para el medio ambiente y sus consumidores o usuarios. Las compañías actualmente son las encargadas de establecer los procesos que generen valor agregado a los clientes cumpliendo con la responsabilidad empresarial y el consumo sustentable. Del mismo modo, todas las áreas de la empresa deben estar orientadas a la construcción de relaciones sociales, comerciales y emocionales con los clientes, adaptándose a la realidad y estilos de vidas actuales. Las marcas internacionales en la actualidad desarrollan alternativas y programas más responsables con el medio ambiente.

De acuerdo con Borin, Lindsey-Mullikin y Krishnan (2013:119) ${ }^{66}$ actualmente las marcas internacionales están apostando por extender sus surtidos o ampliar sus líneas de productos para incluir una gama de artículos responsables con el medio ambiente, añadiendo incrementalmente componentes ecofriendly con el propósito de obtener ventajas competitivas y alcanzar a nichos de mercados insatisfechos. A través de estas acciones las empresas internacionales inician su proceso de transformación en su identidad e imagen corporativa, presentándose como entidades más conscientes del impacto ambiental relacionado a sus actividades comerciales. Mejorado la imagen empresarial y de marca transmitida a la demanda internacional.

En conclusión, las empresas multinacionales han establecido voluntariamente políticas sustentables destinadas a mitigar los daños producidos por sus actividades comerciales y productivas. Estas políticas sustentables comunican y orientan a todas las subsidiarias los estatutos establecidos por la casa matriz destinados a generar rentabilidad ejerciendo el uso responsable de los recursos naturales, eléctricos y la reducción de emisiones de Gases de Efecto Invernadero, entre otras acciones que el menor impacto negativo al medio ambiente en toda su gestión comercial.

Del mismo modo, las políticas sustentables promueven la equidad social promoviendo la igualdad de género, educativa y el derecho a la salud generando valor añadido a la empresa. Estos aspectos involucran a la sociedad en general, es decir, tanto al personal

\footnotetext{
${ }^{65}$ Sarkar, A., (2012). Green Branding and eco-innovations for evolving a sustainable green marketing strategy. Asia-Pacific Journal of Management Research and Innovation. 8(1), p. 42. DOI: 10.1177/2319510X1200800106. Recuperado 21 de Enero de 2019.https://www.academia.edu/9238214/Green_Branding_and_Ecoinnovations_for_Evolving_a_Sustainable_Green_Marketing_Strategy_Innovation_Additional_services_and_information_for ${ }_{66}^{66}$ Borin, N., Lindsey-Mullikin, J., \& Krishnan, R. (2013). An analysis of consumer reactions to green strategies. Journal of Product \& Brand Management, 22(2), p. 119.DOI 10.1108/10610421311320997. Recuperado el 12 de Abril de 2019. https://www.academia.edu/26519893/An_analysis_of_consumer_reactions_to_green_strategies
} 
interno, externo y a las comunidades. Por medio de estas políticas se establecen estrategias que promuevan los valores corporativos y posibles soluciones con las que la empresa internacional pueda contribuir aminorando los problemas la sociales.

Las estrategias internacionales acompañan las políticas sustentables determinando las acciones y mejoras a implementar en la cadena de valor con el propósito de transformar sus operaciones en ecológicamente responsables. Asimismo, las estrategias sustentables promueven la aplicación de sistemas que contribuyan a reducir el uso y reciclaje de agua, alternativas que mitiguen la emisión de GEI y el trabajo en conjunto entre las empresas multinacionales y las comunidades productoras. Las empresas internacionales fusionan los valores comparativos, las políticas sustentables y sus recursos en el establecimiento de las estrategias responsables con el medio ambiente y la sociedad. 


\section{CAPÍTULO IV PLANIFICACIÓN DE LAS MARCAS INTERNACIONALES}

En el capítulo IV se abordan los indicadores utilizados para la planificación de marcas internacionales, desde la construcción hasta las estrategias empleadas por las empresas. A su vez se presentan las políticas de marcas que le proporcionan atributos al producto físico e imaginario y fundamentan el potencial de la marca sustentable en los mercados internacionales.

\subsection{MARCA INTERNACIONAL}

Es una expresión multisensorial que nutre de interpretaciones a los productos físicos e intangible de la empresa que los fabrica, generando actitudes de compra, comparativas o rechazo y diferenciándolos de la competencia (Hoyos, 2016:15) ${ }^{67}$. El posicionamiento de marca es necesario para la supervivencia y diferenciación en el sector comercial local e internacional, las empresas internacionales apoderadas de estas marcas trabajan en la gestión y control de éstas en los diferentes países destinos. Las marcas internacionales cuentan con registros y presencia comercial en varios países de forma simultánea.

La creación de relaciones de la marca hacia la demanda se elabora a nivel estratégico con el objetivo de establecer fuertes vínculos entre los actuales y potenciales clientes. Las marcas son generadoras de significados, deseos, experiencias e interpolan valores, estos últimos pueden o no ser universales (valores sociales como la inclusión, igualdad social y temas ambientalistas). La gestión de marcas internacionales es dinámica y compleja, el mercado de oferta internacional posee inmersa una cultura que diferencia la visión e interpretación de significados entre los individuos de cada país destino y los de las empresas (Llopis, 2015:27) ${ }^{68}$. Sin embargo, se observa a nivel mundial existe un creciente interés por parte de la demanda, el entorno internacional y empresarial de una mayor conciencia sobre el impacto ambiental.

La administración de la marca se ha convertido en una fortaleza de las empresas para la comercialización de bienes y servicios en los mercados de oferta globales y locales. Las empresas requieren diferenciar sus productos de aquellos elaborados por otros fabricantes, es allí donde surge la necesidad de construir marcas con identidad,

\footnotetext{
${ }^{67}$ Hoyos Ballesteros, R.,(2016). Branding El arte de marcar corazones. Bogotá, Colombia: ECOE ediciones. p. 15 ${ }^{68}$ Llopis Sancho, E.,(2015). Crear la Marca Global Modelo: práctico de creación e internacionalización de Marca. Madrid, España: ESIC, p. 27
} 
personalidad e imagen de productos que trasmitan las acciones empresariales responsables con el medio ambiente y la sociedad en mercados internacionales.

La identidad de marca es la asociación del producto y la imagen que ha desarrollado a nivel de comunicación la empresa. La identidad permite a la demanda visualizar e identificar a nivel psicológico el nombre de la marca con el producto en sí, por ejemplo, cuando se menciona la marca de iluminación y soluciones electrónicas Philips se asocia con productos de calidad, seguridad y alta tecnología e innovación. La demanda relaciona Philips como una empresa ecofriendly debido a la comercialización de su amplio portafolio de productos catalogados Philips Green como por ejemplo los bombillos led. Estos artículos han sido elaborados a través de ECODesing, el programa de sustentabilidad de la empresa enfocado en el desarrollo de productos y tecnologías sustentables tomando en cuenta el consumo e indicadores vinculados al ciclo de vida y cualidades responsables con el medio ambiente. ${ }^{69}$ Además, Phillips cuenta con una visión empresarial orientada a la reducción del impacto ambiental desarrollando planes de mejora continua en todas las áreas de la empresa.

La personalidad de marca consiste en dotar de rasgos propiamente humanos a una empresa o marca con el fin de establecer una conexión emocional y cercana con la demanda. De este modo, Nissan Leaf representa a un hombre trabajador, ambientalista y socialmente comprometido. Este automóvil que funciona con un sistema eléctrico que no genera dióxido de carbono. Este modelo de vehículo cuenta con la posibilidad de limitar el rendimiento del motor para ahorrar más energía y con la opción de recargar la batería del auto a través de la selección de modo B que aplica una frenada regenerativa. ${ }^{70}$ Asimismo, Nissan ha trabajado desde 2010 en el desarrollo e innovación de automóviles que fortalezcan su negocio y colaboren en disminuir el impacto ambiental. Para ello, la empresa ha implementado una política de sustentabilidad que integra a toda la gestión empresarial y desarrollo de productos a través de acciones y controles que les permitan alcanzar sus objetivos.

La imagen de marca se relaciona directamente con la identidad marcaria por medio de caracteres gráficos (colorimetría, formas, texturas, tipografía, nombre de marca e

\footnotetext{
${ }^{69}$ Sustentable innovation by desing. Recuperado de https://www.philips.com/aw/about/sustainability/ecodesign.html

${ }^{70}$ Nuevo Nissan Leaf Autonomia y Recarga. Recuperado de https://www.nissan.com.ar/vehiculos/nuevos/nissan-leaf/autonomia-recarga.html
} 
ilustraciones). Estos elementos junto a la comunicación realizada por la empresa intervienen en la percepción de la demanda sobre la marca y de sus productos dotándolos de cualidades que generan un atractivo o emociones sobre ellas. Un ejemplo de ello es Chevrolet que a través su largar trayectoria en el sector automotriz ha desarrollado una imagen de autos modernos, de calidad y resistentes orientados a individuos de clase media y media alta. La industria automotriz ha sido una de las causantes del calentamiento global a través de la generación CO2 producido por los automóviles que comercializan. Sin embargo, desde 2014 Chevrolet ha sacado al mercado internacional sus bicicletas eléctricas que invitan a vivir y disfrutar la vida sin ocasionar daños al medio ambiente, mejorando la imagen de marca por medio del producto físico y el producto imaginario que se relaciona con los valores e identidad de marca responsable con los problemas ambientales. ${ }^{71}$ Chevrolet ha trabajado en los últimos años en una política de mejoras continuas en todas las áreas de la empresa y también ha desarrollado vehículos con el objetivo de generar un impacto positivo con el medio ambiente.

\subsection{POLÍTICA DE MARCA}

La política de marca contribuye a la creación de valor de la marca internacional, estableciendo los principios básicos sobres los cuales se fundamenta el producto físico e imaginario. Estas políticas permitirán expresar con claridad y coherencia la oferta de la empresa a través del portafolio de productos y de sus posicionamientos. Del mismo modo, las políticas de marca permiten construir una relación simbólica sustentada en los valores compartidos por la empresa y la demanda internacional.

Las marcas internacionales son generadoras de cualidades y atributos que se transfieren a los productos que comercializan. Para ello, la marca requiere la funcionalidad y los aspectos propios del producto físico que sustenten su identidad e imagen, cumpliendo con el oficio requerido por el usuario o consumidor. A su vez, el producto físico se apoya en la subjetividad y en la promesa de marca que le confiere el producto imaginario por medio de las asociaciones producidas por la racionalidad, el vínculo emocional y la comunicación empresarial.

Los atributos intrínsecos, externos e intangibles componen el producto internacional sembrando los cimientos para el diseño y desarrollo de estrategias de marcas de

\footnotetext{
${ }^{71}$ RECUPERADO https://www.chevrolet.com.ec/bikes
} 
productos internacionales. Los atributos intrínsecos son aquellos que involucran la composición, diseño y calidad del producto físico como por ejemplo las zapatillas deportivas Futurecraft.Loop de la marca multinacional Adidas, están elaboradas con poliuretano termoplástico reciclado de los océanos que poseen características como la elasticidad, resistencia al aceite, abrasión, desgaste, capacidad de amortiguación y recuperación elástica. A través del diseño industrial aplicado estas zapatillas pueden ser regeneradas debido que en su elaboración se empleó una técnica que fusiona con calor todas las piezas que la componen dejando de lado los pegamentos que dificultan el proceso de reutilización de los materiales. ${ }^{72}$

A su vez, otros modelos de zapatillas deportivas cuentan con el respaldo de Parley, una organización orientada a proteger, divulgar y abordar los problemas ambientales relacionados a la contaminación ambiental en los océanos por causa del plástico. Parley colabora en la recolección y transformación de desechos plásticos rescatados de las costas y océanos del mundo, destinados a la composición de zapatillas elaboradas por Adidas. Este aval le proporciona a la demanda confianza sobre la confección del producto físico sustentable. ${ }^{73}$

Por otra parte, el producto físico requiere diferenciarse en los mercados internacionales y locales del resto de la oferta de artículos sustentables, es allí donde los atributos externos cobran importancia y le confieren cualidades distintivas al artículo por medio del envase, embalaje y la etiqueta. Estos atributos pueden apreciarse en la nueva línea de acondicionares Dove elaborada con un recipiente de plástico de origen vegetal a base de caña de azúcar, utilizando el $80 \%$ de energía renovable para su fabricación. ${ }^{74}$ El formato de este envase está diseñado para amoldarse a la forma de la mano facilitando la extracción de su contenido, además la tapa queda como base para sostener todo el recipiente disminuyendo el desperdicio de producto. Cabe destacar que este artículo se comercializa sin embalaje para el consumo personal de la demanda, es decir, solo cuenta con el recipiente que contiene el producto siendo este una cualidad de este tipo de surtidos.

Con relación a lo expuesto con anterioridad esta línea de acondicionadores Dove mantiene en la etiqueta del producto los colores corporativos y estilo de tipografía de la

\footnotetext{
${ }^{72} \mathrm{https} / / / \mathrm{www}$. adidas.com.ar/futurecraft

73 https://www.adidas.com.ar/blog/361051

${ }^{74} \mathrm{https}$ ://www.lanacion.com.ar/lifestyle/revolucion-greenque-es-plastico-origen-vegetal-nid2192419
} 
marca. En el área fontal del recipiente se observa el isologo de la marca junto a elementos gráficos que resaltan la profundidad de línea del producto sustentable (factor $40,50$ y 60$),{ }^{75}$ también se visualiza la promesa de marca (repara el cabello en 1 minuto), en el reverso cuenta con la descripción, instrucciones y certificación de productos.

Los atributos intangibles se convierten en la promesa de marca del producto físico apelando a los deseos y emociones de los clientes. Sin embargo, aumentar excesivamente la funcionalidad real del producto físico repercute de manera negativa sobre la demanda, causando decepción y desilusión sobre el producto real e imaginario. Estos atributos están conformados por la marca, made in y la garantía que permiten generar vínculos entre el producto y la demanda.

Coca Cola Company comercializa para Argentina la marca Bonaqua, es una marca que evoca la sensación de colaborar por un mundo más limpio y con menos generación de desechos (esta empresa crea envases reciclados y estimula a la demanda a participar de forma activa reduciendo el tamaño del recipiente para luego reciclarlo en el tacho de basura correspondiente), esto se observa a través de los mensajes corporativos emitidos en los medios de comunicación y la publicidad del producto. Este mensaje se refuerza por de medio de su logotipo conformado por el símbolo del infinito que se interpreta de dos maneras interrelacionadas: la primera consiste en la acción de girar el recipiente para ser reciclado y la segunda se refiere al ciclo de vida del recipiente que pude ser reutilizado para la elaboración de un nuevo envase regresando al mercado como un producto trasformado. Del mismo modo, junto al logotipo de la marca tiene una hoja de árbol color verde con un llamado de acción (dale la vuela) y a su derecha el nombre de la marca en color azul que se vincula a la pureza del agua mineral, estos elementos fortalecen la visión sustentable de la marca en el inconsciente de la demanda. ${ }^{76}$

Por su parte, Coca Cola Company respalda su marca de agua confiriéndole estándares de calidad y desarrollo de productos al ser asociada con el país de origen de la empresa (Estados Unidos). Asimismo, el aval empresarial que sustenta a Bonaqua le adjudica seguridad y confianza a los clientes sobre el producto que adquieren por el alto prestigio y reconocimiento de la marca a nivel global. 


\subsection{ESTRATEGIAS DE MARCA INTERNACIONAL SUSTENTABLES}

Las estrategias de marcas están orientadas a definir el respaldo que sustentará o no el producto imaginario. Los criterios estratégicos de marca permitirán discernir la importancia que tiene para el producto imaginario contar con el aval empresarial o por el contrario se aplicará una estrategia segmentada, un ejemplo de ello, es que las empresas fabrican y comercializan varias marcas adaptadas a diferentes segmentos de mercado $o$ pueden estar destinadas a cubrir la demanda de un sector específico fragmentando las marcas de acuerdo con las necesidades de cada mercado o industria internacional.

La relación entre los nombres de las marcas corporativas y las marcas de los artículos establecen una asociación psicológica con el producto imaginario proporcionándole ventajas competitivas al producto físico. Esta estrategia es conocida como extensión de marca y se observa cuando el nombre de la marca corporativa se reencuentra en el nombre de la nueva marca de producto como sucede con Apple y sus líneas Apple TV, Apple Watch e incluso lo expande hasta sus servicios de venta B2C (Apple Store). Esta empresa se ha caracterizado por ser pionera en el desarrollo de productos innovadores de una forma creativa y comprometida con los grandes cambios, un ejemplo de ello ha sido su disposición de contribuir por un mundo más limpio, utilizando aluminio $100 \%$ reciclable en la fabricación de sus líneas de computadores portátiles, adaptando sus instalaciones para el uso de energía renovable, mejorando el diseño de sus productos para que tenga mayor resistencia, entre otras. ${ }^{77}$

En el mercado de oferta internacional es posible encontrar marcas que varían de acuerdo con el país destino, esta estrategia tiende a realizarse cuando las características culturales y locales de un país destino son muy fuertes y poco permeables. Al analizar Bon Aqua en Latinoamérica se observó que cambia el nombre de la marca de acuerdo con el país donde se comercialice un ejemplo puntual sería la comparación con la marca ofertada para Venezuela llamada Nevada mientras que para Chile es conocida como Vital y para Colombia la marca comercializada es Brisa. Sin embargo, la identidad, personalidad e imagen de la marca se mantiene en todos los países destinos representando frescura, el uso responsable de los recursos, protección del medioambiente a través de su envase y la comunicación que promueven el reciclaje.

\footnotetext{
${ }^{77}$ Recuperado el dehttps://www.apple.com/la/environment/
} 
La trasmisión de valor y ventaja competitiva de la marca corporativa a todo el portafolio de producto de la empresa es una estrategia de marca global implementada por empresas como Mondelez, Arcor, Unilever, Coca Cola Company, Nestlé y Pepsico con el objetivo de respaldar las marcas de los diferentes artículos que comercializan en los mercados de oferta internacionales. En los mercados de segmentos universales esta estrategia les confiere a sus marcas ventajas competitivas vinculadas al reconocimiento de marca y el ideal de ella en la mente de la demanda. Sin embargo, se corre un gran riesgo en caso de tener algún percance en las acciones gestionadas por la empresa. Es importante mencionar que las empresas que aplican estas estrategias de marca son aquellas con un alto nivel de internacionalización, además cuentan con grandes capacidades y recursos productivos para abastecer varios países destinos.

Un ejemplo puntual de estrategia global sería Mondelez esta marca aplica su respaldo para todos sus productos, es posible apreciarlo al detallar la utilización de su logotipo en todas sus líneas de productos. Aunado a ello, los clientes le atribuyen confianza, emisiones y estándares de calidad al vincular Mondelez con cualquiera de sus marcas de chocolates, debido a la trayectoria y reconocimiento de la empresa. Sin embargo, cada categoría y línea de producto cuenta con su identidad y nombre de marca.

Asimismo, esta empresa cuenta con un programa llamado Cocoa Life, dedicado a la preservación de los recursos utilizados para el cultivo de cacao, fundamentándose en 5 pilares (medio ambiente, agricultura, comunidad, jóvenes y medios de vida), se prevé que estará implementado para el $2025 .^{78}$ Este proyecto junto al uso de aceite de palma aceitera $100 \%$ sustentable y la imagen de marca de la empresa les transfieren a todas sus marcas de Chocolates valores que son apreciados por la demanda internacional. ${ }^{79}$

La estrategia de marca de familia favorece la introducción de nuevos productos tomando en cuenta el reconocimiento y confianza de los compradores. A través de este criterio es posible vincular varios productos con marca. Un ejemplo de ello es la marca de Philip que cuenta con una variedad de surtidos, líneas y profundidad de línea de productos todos avalados por la empresa. Esta empresa tiene una oferta de productos que va desde juegos de productos para bebes hasta artículos tecnológicos especializados para el área de la salud. El desarrollo de productos físicos e imaginarios está orientado a presentar

\footnotetext{
${ }^{78}$ https://www.cocoalife.org

${ }^{79}$ https://ar.mondelezinternational.com > well-being > sostenibilidad
} 
soluciones innovadoras al mercado internacional que permitan disminuir el impacto ambiental causado por la empresa a nivel industrial como por los artículos comercializados. $^{80}$

Por otra parte, existen marcas que no cuentan con el aval comercial de su grupo empresarial, estas se posicionan por sí misma en el mercado doméstico e internacional, convirtiéndose en una marca institucional. El modelo estratégico es aplicado por Adidas Group, una multinacional de origen alemán dueño de las marcas internacionales Adidas y Reebok, entre otras. ${ }^{81}$ Cada una de estas marcas cuenta con una gestión de marca de forma independiente y compiten en el mercado de oferta entre sí. Aunado a ello, esta característica permite desarrollar un mayor potencial de marca y reduce el riesgo empresarial.

Reebok ha puesto en marcha sus proyectos para reducir la huella ambiental, por ejemplo a través de la creación de un modelo de zapatillas elaboradas con maíz y algodón, estas zapatillas casuales no contienen derivados del petróleo ni elementos tóxicos. Asimismo, la empresa ha realizado una campaña llamada Reebok Recicla con el propósito de recolectar zapatillas de la marca que se encuentren en desuso para ser donadas después de su reparación a distintas organizaciones sociales, a cambio cada persona obtendrá un voucher de $30 \%$ para la compra nuevas zapatillas Reebok. ${ }^{82}$

Del mismo modo, es posible observar marcas que se posicionan sustentadas en país que da origen al producto físico confiriéndole atributos positivos promocionados por el país fabricante. Esta estrategia es conocida como marca país y se observan en marcas como Toyota que aprovecha su lugar de origen y su cultura organizacional para fundamentar un alto nivel de innovación y tecnología. Esta empresa ha desarrollado una línea de autos híbridos que complementan su oferta en el sector automovilístico. Prius es un automóvil que cuenta con dos motores uno a combustión y otro a batería, este último se recarga con la batería del vehículo. La batería del auto se recarga cada vez que el conductor detiene el auto o baja la velocidad. Para generar confianza hacia el consumidor sobre esa nueva tecnología, Toyota comercializa el auto Prius con una garantía por 8 años. Una de las particularidades del vehículo es que emite menos emisiones de carbono que un auto

\footnotetext{
${ }^{80}$ Sustentable innovation by desing. Recuperado de https://www.philips.com/aw/about/sustainability/ecodesign.html ${ }^{81}$ https://www.adidas-group.com/en/group/history/

82 https://www.lanacion.com.ar/moda-y-belleza/zapatillas-veganas-se-fabrican-maiz-hongos-algodonnid2295993
} 
convencional. ${ }^{83}$ Esta línea sustentable cuenta con 3 modelos de autos Prius, Mirai, FTEV III. ${ }^{84}$

Por otra parte, el grado de especialización requerido por el producto físico e imaginario determina el uso o no del aval de marca corporativa. Los artículos vinculados al sector tecnológico, automovilístico y de la salud tienden a ser avalados por la marca empresarial, que ha construido una identidad e imagen de marca apoyadas en la innovación y desarrollo de productos. Marcas como Panasonic se han consolidado con una empresa dedicada a la elaboración de productos electrónicos y tecnológicos avalados por la marca comparativa que les confiere a sus televisores econavi y a todos sus artículos: confianza, resistencia, innovación y calidad percibida por la demanda. Aunado a ello, la empresa trabaja en el uso eficiente de la energía comprometiéndose a desarrollar tecnologías orientadas a mejorar el ahorro de energía, a través del uso de hidrógeno entre otras alternativas para la innovación de productos y mejoras en las actividades empresariales. Estos hechos sustentan la identidad de Panasonic como una marca comprometida con el medio ambiente. ${ }^{85}$

Para finalizar, las estrategias de marcas transculturales se destacan por traspasar las barreras culturales y las fronteras geográficas comercializando sus productos en varios mercados internacionales. Esta estrategia requiere adaptar la oferta de productos elaborados por la empresa de acuerdo con los gustos, costumbres, hábitos y deseos de la demanda del país destino. La adaptación del portafolio de productos se realiza modificando atributos intrínsecos, externos e intangibles. PepsiCo Inc. es una empresa de origen estadounidense, que adapta su oferta comercial de acuerdo con las necesidades y gustos de la demanda de cada país destino. Esta empresa tiene un portafolio de productos que incluye bebidas gaseosas, snacks, jugos y productos alimenticios, entre otros. La estrategia de marca transcultural se observa en la marca de gaseosa Pepsi Ex Extra, un nuevo producto lanzado por la empresa para satisfacer los deseos y necesidades de la población japonesa. La nueva Pepsi Ex Extra cuenta con la cualidad de la bebida a base de cola como la tradicional Pepsi-cola con la modificación en la composición del producto físico que le adiciona $38 \mathrm{mg}$ de cafeína en una lata de $200 \mathrm{ml}$. La marca se presenta como un producto cargado de energía y dinamismo, esto se debe a que el producto fue diseñado para ser consumido durante el verano cuando los

\footnotetext{
${ }^{83}$ https://www.toyota.com.ar/prensa/noticias-de-argentina/toyota-argentina-presenta-una-actualizaciondel-pionero-de-los-autos-hibridos-el-toyota-prius

${ }^{84}$ https://www.toyota.com.ar/innovacion/movilidad-sustentable

85 https://www.panasonic.com/ar/corporate/sustainability/eco.html
} 
japoneses deben trabajar extensas jordanas laborales con altas temperaturas por la época del año. ${ }^{86}$

Por otra parte, PepsiCo Inc. se ha comprometido a generar un impacto positivo ambientalmente a través del análisis de toda la cadena de suministro con el objetivo de implementar mejoras progresivamente en toda la estructura empresarial. Por el momento ha desarrollado sistemas que le permiten reducir el uso del agua en sus fábricas siendo galardonados por el Instituto Internacional de Agua en Estocolmo. También han realizado mejoras en el uso racional de la energía eléctrica en sus instalaciones, además han innovado en la creación de un envase a base de recursos completamente biodegradados que disminuyen la generación de dióxido de carbono. ${ }^{87}$

La construcción de marcas sustentables le proporciona a la marca las principales cualidades que la distinguen de la competencia en mercados internacionales y locales. Sin embargo, las marcas se fundamentan en el producto físico e intangible para satisfacer los deseos, necesidades y anhelos de la demanda, dotando los artículos sustentables de atributos intrínsecos, externos e intangibles. Aunado a ello, el papel de las estrategias internacional es aumentar las ventajas competitivas por medio del respaldo empresarial en aquellos casos que la estructura de marca lo requiera.

${ }^{86}$ https://www.pepsi.co.jp/menu.html\#id_products https://www.pepsi.co.jp/menu.html

${ }_{87}$ http://www.pepsicoargentina.com/purpose/performance-with-purpose/planet 


\section{CAPÍTULO V SUSTENTABILIDAD EN LAS MARCAS DE PRODUCTOS INTERNACIONALES}

En el capítulo $V$ se ejemplifican las acciones sustentables implementadas por empresas globales, regionales y con proyección global de origen argentino. Nestlé SA, Natura Cosméticos SA y Grupo Arcor SA, son empresas que han diseñado y establecido políticas sustentables y sociales orientadas al desarrollo creciente de procesos y actividades empresariales responsables con el medio ambiente y la sociedad.

\subsection{NESTLÉ SA Y NESTLÉ ARGETINA SA}

Es una empresa multinacional de origen suizo, fundada en 1866 a través del desarrollo y comercialización de un producto lateo y a base de cereales tostados destinado a alimentar a los infantes de la época. ${ }^{88}$ La casa matriz de la empresa está ubicada en Vaud, Suiza. Por otra parte, la empresa posee subsidiarias productivas y comerciales a nivel mundial. De esta manera la Nestlé SA cubre las necesidades alimenticias de la demanda alrededor del mundo.

Nestlé SA pertenece al sector alimenticio y de bebidas sin alcohol que promueve la salud y nutrición a través de su identidad y comunicación empresarial. Esta empresa ofrece productos como: café, leche, chocolates, saborizantes para leches, helados, aguas minerales y saborizadas, cereales, caldos, alimentos para mascotas, entre otros. Hoy en día Nestlé SA trabaja para adaptar sus actividades operativas, comerciales, y de productos a una visión más responsable con el medio ambiente y la sociedad.

Esta orientación sigue diversas acciones y manifestaciones de grupos ambientalistas que han informado a la población mundial de las prácticas contra los ecosistemas realizadas por las corporaciones, afectando de forma directa la imagen de Nestlé SA y todas sus subsidiarias. Por tal motivo, la casas matriz de la empresa se ha comprometido a evaluar toda la cadena de valor para encontrar las deficiencias, diseñar e implantar actividades sustentables en toda la estructura comercial corporativa. ${ }^{89}$

\footnotetext{
${ }^{88} \mathrm{https}: / / \mathrm{www} \cdot$ nestle.com.ar/sobre-nestle/historia

89 https://www.nestle.com/sites/default/files/assetlibrary/documents/library/documents/corporate_social_responsibility/nestle-in-society-summary-report2016-es.pdf
} 


\subsubsection{EFICIENCIA Y USO RACIONAL DE LOS RECURSOS}

Desde 2007 Nestlé SA estableció una política orientada a la preservación del medio ambiente en todas sus plantas de fabricación y en la administración de todas sus marcas. Es por ello, que Nestlé México SA trabaja contra la escasez de agua que afecta a la población del estado de Jalisco en México, la subsidiaria de la empresa en México estableció la transformación y reutilización del agua extraída de la leche líquida (materia prima para sus productos), a través de un proceso que calienta el agua a presión baja y elimina parte de su contenido hídrico para después condensar el vapor producido, tratarlo y utilizarlo con fines internos. Este proceso permite la obtención de este recurso natural para ser utilizado en las instalaciones de la empresa, sin depender del consumo de agua de la cuidad. Con esta iniciativa la empresa ahorra aproximadamente el volumen diario necesario para llenar una pileta olímpica, es decir la cantidad de agua necesaria para satisfacer el consumo diario de 6.400 personas en México. ${ }^{90}$

En concordancia con las políticas dirigidas a la preservación y uso responsable del agua en el 2017 Nestlé SA certificó ocho plantas embotelladoras ubicadas en Estados Unidos, Pakistán y Canadá bajo el estándar Alliance for Water Stewardship (AWS). Este organismo se dedica a evaluar la obtención de agua dulce, abordando temas sobre el valor de conservación y gobernanza de este recurso natural. Nestlé SA se comprometió a certificar para el 2025 todas sus plantas a nivel mundial con el estándar AWS. Este proyecto permitirá contribuir en el uso consciente y responsable del agua, comprometiendo a toda la cadena de suministro.

A su vez, Nestlé SA reconoce el reto que enfrenta hoy la sociedad y el mundo respecto al cambio climático, su relación con la generación de $\mathrm{CO} 2$, y el uso desproporcionado de la energía eléctrica por parte de las grandes empresas. En respuesta a esta problemática, la empresa ha gestionado proyectos dedicados a la reducción e implementación de energías renovables destacando el convenio realizado con (Ente Nazionale per l'enegia elettrica) ENEL Green Power Panamá. ${ }^{91}$ A través de esta alianza el 100\% de las fábricas y oficinas de Nestlé Panamá funcionan con energía provenientes de paneles solares desde el 2018, evitando así la emisión anual de 10.000 toneladas de CO2. Nestlé Chile $\mathrm{SA}$ tiene proyectos con Metrogas que trabaja con gas natural para reducir las emisiones

\footnotetext{
${ }^{90}$ https://www.nestle.com.mx/media/pressreleases/inaugura-nestl-primera-fbrica-cero-agua-en-el-mundopara-disminuir-en-15-su-consumo-anual-de-agua-en-mxico

${ }^{91}$ https://www.nestle-centroamerica.com/featuredstories/energia-renovable-ya-es-una-realidad-en-lasplantas-nestle
} 
de gases de efecto invernadero. Todas las sucursales realizan esfuerzos para alcanzar los Objetivos de Desarrollo Sostenible de las Naciones Unidas para el 2030. ${ }^{92}$

\subsubsection{COMPROMISO CON LOS DERECHOS HUMANOS}

A nivel productivo Nestlé SA ha desarrollado junto a Rainforest un plan de trabajo que integra a los agricultores para desarrollar técnicas responsables con el medio ambiente como el riego por goteo, la eliminación de pesticidas en las plantas de café y el uso de metodologías tradicionales que los ayuden a mejorar el producto final. ${ }^{93} \mathrm{~A}$ su vez, Nescafé Plan promueve la creación de valor entre la empresa, sus proveedores y la comunidad a través de la capacitación de buenas prácticas sustentables que beneficien al negocio cafetero sin comprometer a las generaciones futuras.

La casa matriz de la empresa cuenta con proyectos asociados a la lucha por la igualdad social, siendo este un derecho humano que a nivel mundial ha sido aludido por años. Por ello, Nestlé SA ha creado el programa granjeras promotoras dedicado a capacitar a mujeres del sector cafetalero, sobre técnicas de producción, liderazgo y educación sanitaria para que puedan desarrollarse en esta industria que está considerado como un sector para hombres. Asimismo, la empresa cuenta con políticas internas de inclusión y diversidad para impulsar el respeto, dignidad e igualdad de oportunidades para todos. Las políticas de diversidad e inclusión forman parte de las iniciativas globales y locales de la empresa, de las cuales se destacan: las políticas de protección de la maternidad, los entornos de trabajo flexible y de apoyo, talleres de sesgo inconsciente, igualdad de oportunidades de empleo y ofertas de trabajo inclusivo para personas con discapacidad, entre otros. ${ }^{94}$

Nestlé SA reconoce que existen países con dificultades para obtener agua. Esta dificultad desencadena un sinfín de problemas como la desnutrición, deshidratación, diabetes, colesterol alto, entre otras. Por tal motivo, la empresa coopera junto a la Federación Internacional de la Cruz Roja para ayudar a mejorar la calidad de vida de las comunidades africanas, mediante un proyecto que abastece agua potable, sistemas de saneamiento y educación sobre higiene que realizó en Costa de Marfil. Se prevén otros proyectos sociales en Ghana y Etiopía. ${ }^{95}$

\footnotetext{
${ }^{92}$ https://www.nestle.cl/media/pressreleases/mejoras-en-eficiencia-energetica

93 https://www.rainforest-alliance.org/lang/es/newsroom/press-releases/nescafe-release-esp2010

94 https://www.nestle.com.ar/buscar-trabajos/diversidad-e-inclusion

95 https://empresa.nestle.es/es/nuestras-historias/comunidades-con-acceso-a-agua-potable-saludable
} 


\subsubsection{BUENAS PRACTICAS SUSTENTABLES}

Durante el 2010 Nestlé SA sufrió un fuerte boycott después de una investigación realizada por la ONG Greenpeace que puso a la luz el incumplimiento de leyes en Indonesia, originando la desforestación de bosques que forman parte del habitad de una especie de orangután protegida amenazada de extinción. El problema era causado por Cargil la empresa proveedora de palma de aceite para la elaboración de la marca Kit Kat. Este inconveniente desencadenó una serie de acciones por parte de Nestlé SA que afectaron aún más la imagen e identidad de la marca. Tras varias movilizaciones, campañas online y protestas, el CEO de Nestlé SA Paul Bulcke emitió un comunicado en el que planteaba los objetivos medio ambientales a cumplir por la compañía antes del 2020, destacando que para finales de ese año la empresa obtendría la certificación de uso de palma de aceite $100 \%$ sustentable. ${ }^{96}$

A su vez, el uso del plástico está ocasionando estragos a nivel ambiental desde su producción, uso y su posterior desecho. Por ello, organizaciones y movimiento como Breakfreeforplastic, Greenpeace, WWF, Parley, entre otras; trabajan en contra de la generación de desechos plásticos que terminan generalmente contaminando vertientes hidrográficas, océanos, suelos y otras áreas naturales, ocasionando graves problemas ambientales. Para afrontar esta problemática Nestlé SA trabaja junto a un grupo de profesionales y científicos en el Nestlé Institute for Packaging Sciences en la creación de componentes a base de papel, polímeros biodegradables, entre otros materiales alternativos sustentables. ${ }^{97}$

Adicionalmente, Nestlé SA junto a Danimer Scientific realiza esfuerzos en desarrollar una botella biodegradable como envase para la venta de aguas minerales. De acuerdo con la Universidad de Georgia el polímero Nodax es altamente biodegradable, este sería el componente que dará origen a los recipientes para las marcas de agua embotelladas de la empresa como una alternativa para solucionar el problema de la proliferación de botellas de agua en los espacios naturales. ${ }^{98}$

\footnotetext{
${ }^{96} \mathrm{http} / / /$ archivo-es.greenpeace.org/espana/es/news/2010/November/100318-02/

${ }^{97}$ https://www.nestle.com/media/pressreleases/allpressreleases/nestle-inaugurates-packaging-researchinstitute

$\frac{98}{9 t t p s: / / w w w . n e s t l e . c o m / m e d i a / p r e s s r e l e a s e s / a l l p r e s s r e l e a s e s / n e s t l e-d a n i m e r-s c i e n t i f i c-d e v e l o p-~}$ biodegradable-water-bottle
} 
En concordancia con lo expuesto con anterioridad, Nesquik la marca de bebida chocolatada ha reemplazado sus envases y empaques originales por unos elaborados con papel reciclable elaborado con ingredientes $100 \%$ naturales. Este recipiente proviene de fuentes sustentables y cuenta con la certificación FSC (Forest Stewardship Council), una certificación global, sin ánimo de lucro que se dedica a promover la gestión forestal responsable. El producto indica en su referencia que está elaborado con cacao de África Occidental bajo estándares sustentables mediante el proyecto Nestlé Cocoa Plan. ${ }^{99}$ Este producto por el momento solo está disponible en 5 países europeos España, Francia, Alemania, Italia y Portugal.

Aunado a ello esta empresa ha logrado traspasar las fronteras culturales con éxito en todos los países destinos donde comercializa sus productos, Nesquik es uno de los productos más conocidos de la industria alimenticia. Esta marca se comercializa en Argentina en tres presentaciones diferentes (chocolate en polvo, chocolate en polvo con cereal y chocolatada liquida). Mientras que en Colombia línea y la profundidad de línea de este producto es mayor ofreciendo al mercado Nesquik sabor a vainilla, chocolate y fresa además de incluir la marca Milo que es una bebida chocolatada con malta en polvo. Estas diferencias se deben a las características culturales de la población de cada país que conllevan a las marcas internacionales a tomar en cuenta los indicadores culturales para cada mercado destino. ${ }^{100}$

\subsubsection{POLÍTICAS Y ESTRATEGIAS DE SUSTENTABILIDAD NESTLÉ ARGENTINA SA}

Nestlé Argentina SA tiene presencia desde 1930 y cuenta con siete instalaciones productivas destinadas al procesamiento de materia prima y fabricación de los productos comercializados en el país. ${ }^{101}$ Esta subsidiaria acorde con la orientación sustentable establecida por la casa matriz de la empresa ha desarrollado un plan responsable con el medio ambiente, tomando en cuenta a todas las partes involucradas en los procesos de fabricación de productos. Acorde a ello, la empresa ha implementado un sistema que le permite analizar la evolución de las acciones instauradas en relación con el uso adecuado de energía, agua y generación de residuos por tonelada producida.

\footnotetext{
${ }^{99}$ https://www.nestle.com/media/news/nesquik-launches-all-natural-cocoa-powder-in-recyclable-paperpackaging

100 https://www.nesquik.com/es/products

101 https://www.nestle.com.ar/sobre-nestle/nestle-en-argentina
} 
Nestlé Argentina SA ha desarrollado planes en función las políticas sustentables fundamentadas en el uso responsable del agua, energía eléctrica y generación de residuos cero. En relación con estas políticas Nestlé Argentina SA informo que para el 2020 todas sus fábricas establecidas en el territorio nacional se abastecerían al $100 \%$ de energía eléctrica provenientes de fuentes renovables a través de un convenio realizado con YPF una empresa de energía integral argentina. Aunado a ello, a través de acciones orientadas al reciclaje, compostaje y la revalorización energética del $100 \%$ de los residuos generados es las fábricas ubicadas en Argentina han alcanzado la tasa cero residuos enviados a vertederos. Para finalizar en respuesta a la problemática hidráulica las fábricas iniciaron el proceso para la obtención de esta acreditación Alliance for Water Stewardship desde $2018 .^{102}$

Del mismo modo, Nestlé Argentina SA proporciona asistencia a los productores de leche por medio de un proyecto dedicado a capacitar a los tamberos, productores y técnicos sobre metodologías sustentables que pueden aplicar dentro de su labor diaria. Además, este proyecto incluye actividades relacionadas a la producción de cultivo ecofriendly para el consumo pastoril, el cuidado consciente del agua, la conservación del suelo, el ahorro energético y la disminución de los residuos contenientes. Aunado a ello este programa trabaja en generar conciencia a los productores sobre la lucha contra el trabajo ilegal, promover condiciones de trabajo dignas y el rechazo al trabajo infantil. ${ }^{103}$

\subsection{NATURA COSMÉTICOS SA}

Natura Cosméticos SA es una empresa regional fundada en Brasil, fundada en 1969 en Sao Pablo lugar donde se encuentran las instalaciones de la casa matriz. Esta empresa se dedica a la elaboración de productos de belleza, higiene personal y perfumería con presencia en el Argentina, Brasil, Colombia, México, Chile, Perú, EE. UU., Francia y Australia. ${ }^{104}$ Natura Cosméticos SA solo posee subsidiarias comerciales en los países descritos con anterioridad a excepción de Brasil, donde cuenta con dos instalaciones productivas.

Natura Cosméticos SA se caracteriza por ser una empresa comprometida a trabajar bajo la filosofía del desarrollo sustentable involucrando aspectos económicos, sociales y

\footnotetext{
${ }^{102}$ https://www.nestle.com.ar/media/pressreleases/comprometidos-con-el-uso-responsable-del-agua

103 https://www.nestle.com.ar/nestle-en-sociedad/servicio-al-productor-lechero

104 https://www.naturacosmeticos.com.ar/la-natura/nuestra-historia
} 
ambientales. La casa matriz promueve estos principios en todas sus actividades. Natura Cosméticos SA evalúa y controla todas las operaciones de la cadena de suministro a través de indicadores orientados al desarrollo sustentable, con el de propósito de mejorar cada día la oferta de valor de la empresa. ${ }^{105}$

\subsubsection{EFICIENCIA Y USO RACIONAL DE LOS RECURSOS}

Natura Cosméticos SA se caracteriza por la preservación y el cuidado ambiental. Una de las acciones de la casa matriz de la empresa es la promoción del uso equitativo y eficiente del agua proveniente de efluentes sanitarios. Estas aguas residuales pasan por procesos fisicoquímicos y biológicos en las estaciones de tratamiento de la fábrica de Cajamar para su posterior uso en sanitarios y limpieza. ${ }^{106}$

La casa matriz de la empresa instauró en toda la cadena de valor el objetivo de tener emisiones de carbono neutrales. Una de las alternativas implementadas por la empresa ha sido priorizar el uso de transporte marítimo y fluvial en los países destinos que disponen de esta opción debido a que generan menos carbono que los otros modos de transporte. Aunado a ello, desde 2013 Natura opera en América Latina con camiones que se cargan con etanol a diferencia de los tradicionales que utilizan combustibles. Así, los colaboradores de la empresa se desplazan diariamente a la planta ubicada en Cajamar mediante un autobús que utiliza etanol para su funcionamiento. ${ }^{107}$

Asimismo, las emisiones de $\mathrm{CO} 2$ que Natura Cosméticos SA no puede evitar son compensadas $100 \%$ de manera voluntaria por medio de la compra de bonos de carbono a empresa que hayan reducido las emisiones de dióxido de carbono a través de proyectos dirigidos a proteger los bosques de la desforestación, la sustitución de combustible fósil con de eficiencia eléctrica. ${ }^{108} \mathrm{De}$ esta manera la casa matriz busca mantener la reducción de impacto negativo ocasionado por las actividades productivas y comerciales de la empresa.

Natura Cosméticos SA cuenta con tres certificaciones que avalan la sustentabilidad empresarial, garantizando a los clientes y compradores ecológicos que los productos

\footnotetext{
${ }^{105}$ https://js.rede.natura.net/html/home/2019/agosto/informe_anual_natura_2018.pdf pagina 44

106 https://www.relatoweb.com.br/natura/13/es/agua

${ }^{107}$ https://www.relatoweb.com.br/natura/13/sites/default/files/rel_natura_2013_fo_impresso_miolo_espa nhol_duplas.pdf pagina 11

108 https://www.naturacosmeticos.com.ar/blog/sustentabilidad/compromiso-con-el-clima
} 
comercializados por la empresa cuentan con las características sustentables que comunican. ${ }^{109} \mathrm{La}$ certificación $\mathrm{B}$ hace referencia a la transparencia, buenas prácticas y al cumplimiento de estándares de responsabilidad social y ambiental por parte de la empresa en todas sus actividades comerciales.

\subsubsection{COMPROMISO CON LOS DERECHOS HUMANOS}

Natura Cosméticos SA realiza capacitaciones a las comunidades de agricultores orientadas a la regularización ambiental sobre técnicas y estatutos sustentables, trayendo como consecuencia la reducción de no conformidades ambientales reconocidas por su sistema de verificación ${ }^{110}$. Estas acciones promueven el vínculo entre la cadena de suministro y la empresa mejorando las relaciones comerciales. Este trabajo en conjunto sustenta la identidad de la empresa que se proyecta en productos de calidad, que satisfagan las necesidades relacionadas a la higiene y el cuidado personal de los individuos sin sacrificar el bienestar social, ambiental y la rentabilidad empresarial.

Natura Cosméticos SA es consciente de los problemas que padece la región latinoamericana vinculados a la desigualdad social, reduciendo la posibilidad de desarrollo profesional, económico y productivos de las poblaciones y países latinoamericanos. En relación con esta problemática la casa matriz de la empresa ha desarrollado un programa destinado a recaudar el 100\% de sus ganancias obtenidas de la venta de sus productos no cosméticos (porta cosméticos, agendas, botellas de agua, entre otros) para actividades educativas. Este programa tiene como objetivo disminuir los índices de abandono y repetición escolar, aumentar la participación solidaria a través de actividades dinámicas donde se involucren alumnos, profesores y familias. En el 2017 este programa creció un $5,9 \%$ en comparación con el $2016 .{ }^{111}$

Natura Cosméticos SA ha creado un proyecto con el propósito de incentivar a sus consultoras y a sus familiares a matricularse en instituciones de educación técnicas o superior, idiomas y cursos de lectura entre otros, obteniendo descuentos para el ingreso a centros de estudios. Del mismo modo, la empresa cuenta con un plan de servicios médicos con un descuento del $60 \%$ cubriendo las consultas médicas, exámenes y

\footnotetext{
${ }^{109}$ https://www.naturacosmeticos.com.ar/blog/sustentabilidad/b-corp-la-certificacion-comprueba-quenatura-avala-el-crecimiento-y-la?consultoria=delasprieto ${ }^{110}$ https://www.natura.com.mx/sites/all/modules/downloads/pdf/natura-informe-gri-2017.pdf 44-46 ${ }_{111}$ https://www.natura.com.mx/sites/all/modules/downloads/pdf/natura-informe-gri-2017.pdf 54
} 
medicamentos, además de canal de asistencia y contención en situación de violencia de género para su personal. ${ }^{112}$

\subsubsection{BUENAS PRACTICAS SUSTENTABLES}

La gestión empresarial de la casa matriz de Natura Cosméticos SA se basa en el desarrollo sustentable involucrando a todas las áreas de la empresa, a sus proveedores y colaboradores para alcanzar el objetivo de generar un impacto positivo ambiental, social, económico y cultural en el sector de cosméticos. Para ello, Natura Cosméticos SA ha implementado mejoras a lo largo de la cadena de suministro, permitiéndole obtener certificaciones que avalen la sustentabilidad de la empresa.

Todos los productos Natura cuentan con la certificación Leaping Bunny de Cruelty Free International desde 2018, lo que indica que sus productos no han sido testeados en animales y sus componentes no contienen ingredientes de origen animal. La empresa realiza pruebas con equipos de última tecnología y trabaja junto a laboratorios y académicos con el propósito de innovar sus productos, garantizar la seguridad y salud de sus clientes. ${ }^{113}$ Natura se siente comprometida en promover la eliminación de pruebas con animales, siendo esta una práctica cruel y habitual relacionada al sector cosmético a nivel local e internacional.

A su vez, la línea Ekos es portadora sello UEBT (La Unión para el Comercio Ético) una asociación sin fines de lucro que certifica el compromiso de la marca con la conservación de la biodiversidad, las prácticas de abastecimiento y los conocimientos tradicionales de las comunidades que participan activamente en el cultivo y recolección de materia prima. Asimismo, esta asociación avala que la materia prima de esta línea de productos es de origen vegetal ${ }^{114}$. Del mismo modo, la línea de productos Ekos que cuenta con envases y embalajes elaborados con material reciclado que contribuyen con los objetivos planteados por la marca, siendo esta la línea que evoca ser la más sustentable de todos los productos de la empresa.

\footnotetext{
${ }^{112}$ https://www.natura.com.mx/sites/all/modules/downloads/pdf/natura-informe-gri-2017.pdf 49-50

${ }_{113}$ https://www.naturacosmeticos.com.ar/blog/sustentabilidad/natura-obtuvo-el-sello-leaping-bunny-decruelty-free-international

${ }^{114}$ https://www.naturacosmeticos.com.ar/blog/sustentabilidad/con-el-sello-uebt-ekos-muestra-su-respetopor-la-biodiversidad
} 
Aunado a ello, la oferta de envases plásticos para realizar refill para su línea de cremas Tododía y toda la línea Ekos son fabricados a base de caña de azúcar y no de petroquímicos como los convencionales (son llamados plástico verde y son $100 \%$ reciclables), incentivando la reutilización de los envases adquiridos por los compradores y clientes en su primera compra. Del mismo modo, todos los recipientes Natura cuentan con un diseño ergonómico que le otorgan practicidad y facilidad de uso a la demanda. Estos productos cuentan con $68.62 \%$ de materia de embalaje reciclable. ${ }^{115}$

En el 2011 Natura Cosméticos SA redujo el formato y la cantidad de páginas que tenía su catálogo de revistas con el propósito de aprovechar los materiales y producir un menor desperdicio. A su vez fueron modificados los tamaños de las cajas de productos por unos más pequeños que son más eficientes y cómodos al momento de la entrega de los artículos vendidos. Del mismo modo, redujo el uso de energía mediante la instalación de paneles solares en las plantas de fabricación que representan un consumo más sustentable.

Por otra parte, la oferta de productos Natura Cosméticos SA varía en cada país destino en el caso puntual de Argentina la empresa promociona 25 líneas de productos que comprende desde artículos del cuidado personal como cremas corporales, jabones, cremas para el rosto, maquillaje, shampoo, acondicionador, protectores solares, perfumes para dama y caballero, entre otros. ${ }^{116}$ En Francia el portafolio de productos se reduce a siete en la comercialización de líneas de artículos dejando de lado productos como maquillaje y protectores solares, debido a las diferencias culturales de la demanda en cada país destino. ${ }^{117}$ Las mujeres latinoamericanas se preocupan por su apariencia, cuidan de su imagen y de cómo se proyectan al mundo en contraste con las mujeres europeas que suelen ser muy naturales y sencillas con su apariencia física.

\subsubsection{POLÍTICAS Y ESTRATEGIAS DE SUSTENTABILIDAD NATURA COSMÉTICOS SA EN ARGENTINA}

Natura Cosméticos SA en Argentina cuenta con subsidiaria comercial desde 1992 que se encarga de dirigir las operaciones comerciales y de distribución en Argentina, Uruguay y Paraguay. Como parte de las acciones sustentables la subsidiaria argentina ha adquirido setenta mil bonos de carbono del mercado voluntario a la empresa local Parque Eólico

\footnotetext{
${ }^{115} \mathrm{https://www.naturacosmeticos.com.ar/blog/sustentabilidad/envases-ecodisenados}$

116 https://www.naturacosmeticos.com.ar/

117 https://www.naturabrasil.fr/fr-fr/soins-cheveux/
} 
Rawson de Genneia convirtiéndose en la primera inversión de esta envergadura de la empresa en territorio argentino. ${ }^{118}$ Esta acción se debe a la evaluación de proyectos locales orientados a la disminución de las emisiones de CO2 en Argentina.

En conformidad al proyecto destinado a la transformación de la sociedad a través de la educación. Natura Cosméticos SA en Argentina apoya a cuarenta y cinco centros de estudios en veinticuatro provincias. Esta iniciativa busca reducir los niveles de analfabetismo realizando donaciones económicas, materiales escolares, capacitaciones presenciales y online para el desarrollo y la implementación de los proyectos educativos. Este programa cuenta con el apoyo de CLAYSS (centro latinoamericano de aprendizaje y servicio) en la realización de cursos presenciales y online capacitando a directivos, docentes y estudiantes en las metodologías y prácticas solidarias para el desarrollo e implementación de proyectos educativos que promuevan la alfabetización y la lectura de las comunidades, la realización material ortopédicos para donar, la elaboración de material didáctico para niños autistas, entre otras actividades ${ }^{119}$.

\subsection{GRUPO ARCOR SA}

Grupo Arcor SA es una empresa de origen argentino con presencia global especializada en la elaboración de golosinas y productos alimenticios, implementando la estrategia de marca global y de familia para su amplio portafolio de productos. ${ }^{120}$ La casa matriz está ubicada en Córdoba Argentina. La empresa posee en Argentina aproximadamente dieciséis fábricas y una subsidiaria comercial. Estas fábricas producen artículos comestibles a excepción de tres de ellas que están destinadas a la elaboración de cartón corrugado y envases de cartón para el mercado nacional e internacional.

La actividad comercial y productiva de Grupo Arcor SA está orientada a la responsabilidad social y ambiental. Para lograrlo, la casa matriz diseña e implementa proyectos destinados al desarrollo de producto y mejoras en las operaciones y cadena de valor, con la convicción que cada año mejora su rendimiento y compromiso sustentable. ${ }^{121}$

\footnotetext{
${ }^{118}$ https://www.genneia.com.ar/news/natura-compra-70-000-bonos-de-carbono-del-parque-eolicorawson-de-genneia/

${ }^{119} \mathrm{http} / / / \mathrm{www}$.clayss.org.ar/natura/que.html

${ }^{120} \mathrm{https://www.arcor.com/ar/quienes-somos}$

${ }^{121}$ https://www.arcor.com/ar/downloads/Reporte-de-Sustentabilidad-2018-Grupo-Arcor.pdf
} 


\subsubsection{EFICIENCIA Y USO RACIONAL DE LOS RECURSOS}

Grupo Arcor SA investiga la reutilización de agua de lluvia y la recuperación de agua fría en los equipos de enfriamiento en el abastecimiento de agua para los baños. Actualmente las fabricas ubicadas en México, Argentina y Brasil han reducido el consumo de este recurso natural de forma gradual implementando tecnología para el tratamiento de aguas de efluentes tratadas e implementando mejoras en los procesos. ${ }^{122}$

Asimismo, Grupo Arcor SA trabaja en tener un impacto positivo con el medio ambiente implementando mejoras en sus instalaciones. En Argentina la energía eléctrica proviene de fuentes renovables que se obtiene a través de sus tres centrales termoeléctrica alimentadas de gas natural, biomasa y bagazo de caña procedente de la caña de azúcar. El uso de estos materiales ayuda a mitigar la generación de GEI (Gases de Efecto Invernadero) que es el principal causante del calentamiento global. ${ }^{123}$

Grupo Arcor SA cuenta con la iniciativa Agro Sustentable dedicada en asegurar la responsabilidad ambiental, social y económica de los insumos que la empresa adquiere y produce, a través del análisis e implementación de estándares que garanticen la sustentabilidad a largo plazo en la producción de frutas y hortalizas, cacao, leche, pescado, aceite de palma, caña de azúcar, entre otros. ${ }^{124}$

Estas acciones le han permitido obtener certificaciones internacionales Bonsucro, Global Gap y USDA Origanic. A su vez, se encuentran trabajando en implementación de un plan de acción a largo plazo para alcanzar el abastecimiento de aceite de palma $100 \%$ responsable. También se encuentran realizando auditorias en las plantas de Colonia Caroya y Arroyito para obtener la certificación UTZ (significa Buen Café en el dialecto maya) Y RSPO (La Mesa Redonda de Aceite de Palma Sostenible). ${ }^{125}$

A su vez, Grupo Arcor SA cuenta con una política de abastecimiento de materiales sustentables destinada a la gestión adecuada de bosques con el objetivo de minimizar el impacto ambiental y la desforestación de bosques mediante la compra de productos vírgenes certificados o a base de componentes reciclados. Asimismo, a través de esta política la empresa ha reducido crecientemente en los últimos años el uso del PVC

\footnotetext{
${ }^{122}$ https://www.arcor.com/ar/downloads/Reporte-de-Sustentabilidad-2018-Grupo-Arcor.pdf 79-87

123 https://www.arcor.com/es/downloads/Brochure-2018.pdf pag 5

124 https://www.arcor.com/ar/downloads/Reporte-de-Sustentabilidad-2018-Grupo-Arcor.pdf pag 45-47

125 https://www.arcor.com/ar/downloads/Reporte-de-Sustentabilidad-2017-Grupo-Arcor.pdf 36 - 42
} 
utilizado para la elaboración de envases. Las fabricas Cartocor dedicadas a fabricar bandejas de cartón para la industria láctea cuenta con la certificación FSC (Forest Stewardship Council), que constatan el uso de materiales derivados de espacios forestales que cumplan con características sustentables. ${ }^{126}$

Grupo Arcor SA ha desarrollado tras doce meses y dieciocho ensayos un envase $60 \%$ compostable confeccionado con un bioplástico que proviene del almidón de maíz denominado por la empresa como Politwist. Esta innovación impulsa a la empresa a continuar trabajando para encontrar alternativas de envases ecofriendly para todos sus productos. Por el momento este envase solo cubre la oferta de todas las líneas de la marca Butter Toffees. Este desarrollo demuestra la preocupación de Grupo Arcor SA de gestionar un negocio orientado al bienestar de la demanda y del medio ambiente. ${ }^{127}$

\subsubsection{COMPROMISO CON LOS DERECHOS HUMANOS Y LABORALES}

Grupo Arcor SA trabaja junto a sus proveedores de materia prima capacitándolos y apoyándolo como parte de su plan sustentable. El Proyecto Cobra es un programa iniciado en el 2017 que se centra en un desarrollo integral de quince pequeños productores de caña de azúcar, con el objetivo de reducir la huella ambiental generada por la quema de caña como método de limpieza de rastrojos, promoviendo la reincorporación de los desechos naturales postcosecha al suelo mediante el reemplazo de procedimiento de cosecha manual por la cosecha industrial. Esta técnica permite mejorar la obtención del producto fabril, pues la caña fresca tiene un mayor contenido de sacarosa y esto representa un aumento en la rentabilidad del productor; reduce el tiempo de zafra de 100 a 4 días. ${ }^{128}$

Esta empresa junto a la Universidad Austral de Rosario cuenta con un programa para productores con el objetivo de instruir a sus proveedores de tomate, choclo y durazno sobre prácticas sustentables en los procesos de cultivo y productivos agrícola. Esta iniciativa permite alinear a su filosofía responsable con el medioambiente desde la cadena de suministro hasta la gestión empresarial, consolidando los valores de la marca. $^{129}$

\footnotetext{
${ }^{126}$ https://www.arcor.com/ar/downloads/Reporte-de-Sustentabilidad-2017-Grupo-Arcor.pdf 83-86

127 https://www.arcor.com/ar/downloads/Reporte-de-Sustentabilidad-2018-Grupo-Arcor.pdf 108 -109

128 https://www.arcor.com/ar/downloads/Reporte-de-Sustentabilidad-2018-Grupo-Arcor.pdf pag 48-49

129 https://www.arcor.com/ar/downloads/Reporte-de-Sustentabilidad-2017-Grupo-Arcor.pdf 39
} 
Inclusión y desarrollo profesional son parte de los valores que representa Grupo Arcor SA en sus actividades empresariales. La empresa cuenta con diversos programas para la inserción de nuevos talentos y el respeto por sus colaboradores promoviendo la equidad, diversidad e inclusión. Grupo Arcor SA ha implementado beneficios para las mujeres con niños pequeños a través de apoyo económico, jornada reducida por maternidad, kits escolares, programa de protección a las embarazadas y el 2016 contó con la participación del $47 \%$ de mujeres en el plan emprendedoras en Argentina. También cuenta con un proyecto de inclusión laboral de personas con discapacidad, reclutando, sensibilizando, formando y ofreciendo condiciones de accesibilidad en sus instalaciones. $^{130}$

Grupo Arcor SA desde hace más de 26 años tiene la convicción de poder generar cambios sustanciales en la sociedad, contribuyendo a la generación de igualdad de oportunidades educativa. Para ello, ha creado la Fundación Arcor Argentina, el Instituto Arcor Brasil y la Fundación Arcor Chile, fundamentados en dos pilares: niñez y vida saludable. Ellos buscan promover hábitos de vida saludable y derechos de la niñez. ${ }^{131}$

Durante el 2018 bajo el emblema Niñez y Vida Saludable se desarrollaron varias actividades como la entrega de kits de vida activa y de alimentación saludable, la realización de comedia musical, caminatas, juegos y conferencias; realizando un total de 112 proyectos contando con la participación de 35 mil niños y la formación de 1.716 docentes en Argentina, Brasil y Chile. Respecto a la lucha por los derechos de los niños se realizan capacitaciones y entrega de material didáctico. Del mismo modo, este proyecto cuenta con una revista impresa sobre la niñez y tecnología, en el SITEAL que ha sido desarrollada por El Instituto Internacional de Planeamiento de la Educación de la UNESCO y estrategias digitales integradas que incluyen comunicación regional, portal educativo, entre otras acciones. ${ }^{132}$

\subsubsection{BUENAS PRÁCTICAS SUSTENTABLES}

Grupo Arcor SA ha agregado a su portafolio de productos más de 380 artículos libre de gluten convirtiéndose en la empresa con mayor oferta para abastecer la comunidad celiaca. También ha reducido la cantidad de grasas trans y sodio en todo su producto

\footnotetext{
${ }^{130}$ https://www.arcor.com/ar/downloads/Reporte-de-Sustentabilidad-2017-Grupo-Arcor.pdf 106

131 https://www.fundacionarcor.org/es/que-hacemos/index

132 https://www.fundacionarcor.org/es/biblioteca/detalle/1868/informe-anual-de-actividades-2018 4 - 21
} 
para mejorar las propiedades nutricionales sin sacrificar la calidad y el sabor de su oferta comercial. ${ }^{133}$

La marca de mermeladas comercializada por la empresa cuenta con una línea de mermeladas cero azucares, mediante la sustitución de azúcar tradicional (proveniente de caña de azúcar) por sorbitol y sucralosa. Estos componentes son aprobados por las autoridades médicas, científicas y reguladores de Estados Unidos, la Unión Europea, Canadá, Australia y Nueva Zelanda para su uso en la producción de alimentos. Eso permite elaborar productos saludables para la sociedad y ayuda a disminuir las enfermedades causadas por el consumo de artículos ricos en azúcar. ${ }^{134}$

El programa Tu Porción Justa va destinada al consumo de productos azucarados que contiene la cantidad en gramos definida por la Legislación del Mercosur además de contar con la pauta establecida por la Guía Alimentaria para la Población Alimentaria. Este programa cuenta con un sello identificador para que la demanda reconozca con facilidad aquellos productos que cuenten con esta particularidad. Aunado a ello, la empresa ha incluido en su portafolio de productos un snack saludable bajo el nombre de Natural Break que ofrece variedades de frutos secos. ${ }^{135}$

En conclusión, Nestlé SA, Natura Cosméticos SA y Grupo Arcor SA ha implementado un conjunto de políticas sustentables a través de las cuales se establecen objetivos orientados a la reducción de emisiones Gases de Efecto Invernadero, el consumo responsable de los recursos y el uso de materia prima sustentable. Nestlé SA, Natura Cosméticos SA y Grupo Arcor SA ha implementado el uso de la energía eléctrica provenientes de fuentes renovable a través de convenios o del autoabastecimiento mediante el uso de elementos sustentables como es el caso de Grupo Arcor SA que posee termoeléctricas propias. Las tres empresas trabajan en el reciclaje de agua y su uso adecuado en todos los procesos de la cadena de valor. Las emisiones de GEI son reducidas a través del uso de energía renovable y del desarrollo de productos que contengan una baja de insumos de origen químico (incluyendo el envase, empaque y embalaje) por lo cual se destaca Natura Cosméticos SA.

\footnotetext{
${ }^{133}$ https://www.arcor.com/ar/downloads/Reporte-de-Sustentabilidad-2018-Grupo-Arcor.pdf 69

134 https://www.arcor.com/ar/downloads/Reporte-de-Sustentabilidad-2018-Grupo-Arcor.pdf 163

135 https://www.arcor.com/es/downloads/Brochure-2018.pdf 3
} 
A nivel social Nestlé SA, Natura Cosméticos SA y Grupo Arcor SA han desarrollado programas orientados a capacitar e informar a sus proveedores agrícolas en uso de técnicas que preserven el medio ambiente y ayudándoles a obtener certificaciones que avalen su trabajo. Estas empresas además cuentan con programas dedicados a promover la igualdad social de manera interna y externa. Internamente las tres empresas proporcionan oportunidades de crecimiento laboral indistintamente del género, licencias por maternidad, entre otras actividades. Las acciones sociales externas de estas empresas varían entre sí, sin embargo, las tres ofrecen programas educativos dirigidos a niños de bajos recursos. 


\section{CONCLUSIÓN}

Las marcas multinacionales se ven afectadas por las interpretaciones y percepciones culturales de la demanda internacional. Por tanto, las marcas internacionales requieren ser adaptadas de acuerdo con los valores culturales presenten en el mercado destino. Para ello, la empresa establece las políticas de marcas internacionales que determinan la estructura base para la toma de decisiones estratégicas a implementar en cada mercado internacional.

La problemática ambiental ha impulsado la integración de grupos de personas alrededor del mundo con el propósito de promover un cambio en la gestión empresarial internacional y la conducta de los individuos por una responsable con el medioambiente. A nivel mundial se aprecian cambios en el comportamiento de la demanda internacional relacionadas al consumo, uso y adquisición de productos sustentables.

Las empresas multinacionales sustentables elaboran productos ambientalmente seguros a través del establecimiento de políticas sustentables que comuniquen los objetivos empresariales. De acuerdo con las políticas sustentables se definen las estrategias de las empresas internacionales integrando a toda la cadena de suministro y a la sociedad en las actividades responsables con el medioambiente.

Por otra parte, las estrategias de empresas multinacionales sustentables contemplan además la elaboración de productos internacionales que no dañen al medio ambiente. En este punto el desarrollo productos ambientalmente seguros se apoya en las políticas sustentables para el diseño de nuevos artículos o el ajuste de los productos actuales. Las empresas sustentables aumentan significativamente las ventajas competitivas en los mercados internacionales.

La casa matriz de empresas internacionales establecen un conjunto de políticas con el propósito de organizar las actividades a realizar por todas las subsidiarias. Las políticas empresariales se fundamentan en la identidad, valores e imagen de la corporación y sus marcas internacionales. Cada empresa sustentable de acuerdo con el sector comercial y actividad productiva adecua a su plan estratégico una agrupación de acciones dirigidas a la preservación del medio ambiente y asistir a la sociedad a nivel internacional. Estas acciones voluntarias las realizan las empresas para incrementar la entrega de valor y establecer vínculos emocionales con la demanda internacional. 
Las empresas internacionales que trabaja en el desarrollo de actividades sustentables realizan un gran esfuerzo en adaptar y mejorar sus recursos para mitigar los efectos negativos ocasionados al medio ambiente devengado de su labor empresarial. A través de la ejemplificación de las empresas Nestlé SA, Natura Cosméticos SA, Grupo Arcor SA, se observaron el conjunto de políticas y estrategias aplicadas por cada empresa de acuerdo con su filosofía empresarial, el nivel de internacionalización y su sector comercial. Estas tres empresas trabajan para instaurar el uso eficiente de los recursos naturales y eléctricos, en sus instalaciones.

Para lograrlo Nestlé SA implemento en un sistema que permite la reutilización de agua en su fábrica ubicada en México, además realiza mejoras en los procesos de extracción con los cuales se abastece para la comercialización de sus marcas de aguas embotelladas. Por su parte, Natura Cosméticos SA y Grupo Arcor SA cuentan con un sistema de filtrado y tratamiento propios que les permite trabajar con agua de efluentes. Respecto al uso de energía eléctrica las tres empresas trabajan con la energía de fuentes renovables.

Sin embargo, a nivel de productos se Nestlé SA y Grupo Arcor SA se enfocan en proporcionar productos alimenticios más saludables a través de la reducción y sustitución de componentes azucarados y grasa. Ambas empresas trabajan en el desarrollo de empaques reciclables o que reduzcan la huella ambiental. Por su parte, Natura Cosméticos SA prioriza la producción de artículos que cuenten con una gran proporción de componentes naturales. Además, fábrica de envases con material post consumo y de origen renovable.

Por otra parte, Nestlé SA, Natura Cosméticos SA y Grupo Arcor SA promueve la igualdad de condiciones tanto para sus empleados como para la comunidad, a través de un conjunto de actividades y políticas implementadas por las compañías. Cada empresa cuenta con sus propias actividades mayormente relacionadas a la educación infantil, oportunidades de crecimiento laboral y el otorgamiento de beneficios. 


\section{BIBLIOGRAFÍA}

\section{Libros}

Bradley, F.; Calderon, H., (2006). Marketing Internacional. Madrid, España: Pearson Prentice Hall.

Cubillo, J., Blanco, A.,(2014). Estrategias de Marketing Sectorial. Madrid, España: ESIC.

Christiansen, B.,(2013). Transcultural Marketing for Incremental and Radical Innovation. Estados Unidos de America. Business Sciences References (and imprint by IGI Global).

Fitoussi, J.; Rosanvallon, P., (1996). La nueva era de las desigualdades. Buenos Aires: Argentina, Ediciones Manantial.

Hollensen, S., (2011). Global Marketing: A decision-oriented approach. (5 th ed.). Harlow essex, England: Prentice Hall.

Hoyos Ballesteros, R.,(2016). Branding El arte de marcar corazones. Bogotá, Colombia: ECOE ediciones.

Kotler, Philip (2001). Dirección De Marketing. Distrito Federal, México: Editorial Prentice Hall.

Llopis Sancho, E.,(2015). Crear la Marca Global Modelo: práctico de creación e internacionalización de Marca. Madrid, España: ESIC

Schroeder, J.,(2015). Brands interdisciplinary perspective. Estados Unidos: Taylor and Francis Group

Tharp, M., (2014). Transcultural Marketing. New York, Estados Unidos: Taylor and Francis Group

\section{Revistas Técnicas}


Bernabel, A.,(2015). Identidad y deterioro de imagen de la marca, caso: Calzado deportivos Kelme.Comuni@cción, 7 (1).p. 18-19.

https://www.redalyc.org/pdf/310/31045569006.pdf

Borin, N., Lindsey-Mullikin, J., \& Krishnan, R. (2013). An analysis of consumer reactions to green strategies. Journal of Product \& Brand Management, 22(2), 118-128.DOI 10.1108/10610421311320997. Recuperado el 12 de Abril de 2019.

https://www.academia.edu/26519893/An analysis of consumer reactions to green stra tegies

Cepeda-Palacio, S.,(2014). Alcances actuales del concepto de marca. Un estudio comparativo, en la historia. Entramado, 10(2), 128-142. Recuperado el 6 de Enero de 2019. http://www.scielo.org.co/pdf/entra/v10n2/v10n2a09.pdf

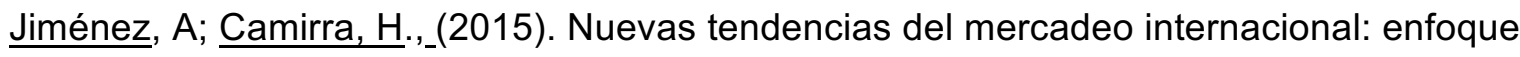
del branding y su vinculación con el consumidor. Economía. XL(40), 171-186.

Recuperado el 13 de Enero de 2019.

https://www.redalyc.org/articulo.oa?id=195648804008

Moreno, H., (2014). La influencia del precio y las estrategias de comunicación visual basadas en simbología cultural sobre la preferencia de marcas ecológicas y consumo sostenible. EAN. (77),168-182. Recuperado 6 de Enero de 2019.

http://www.redalyc.org/articulo.oa?id=20633274012

Sarkar, A., (2012). Green Branding and eco-innovations for evolving a sustainable green marketing strategy. Asia-Pacific Journal of Management Research and Innovation. 8(1), 118-128. DOI: 10.1177/2319510X1200800106. Recuperado 21 de Enero de 2019. https://www.academia.edu/9238214/Green Branding and Ecoinnovations for Evolving a Sustainable Green Marketing Strategy Innovation Addition al services and information for

Tomassini, L., (1996) El proceso de globalización y sus impactos socio-políticos. Estudios Internacionales, 29(115), p. 318.

https://revistaei.uchile.cl/index.php/REl/article/view/15051/29141 
Zwerg, A.,(2008), Incidences and Analyses of Green Marketing Strategy in Colombian Exports, 13, p.12. Recuperado el 12 de Mayo de 2019.

http://www.redalyc.org/articulo.oa?id=322327243001

\section{Sitios Web}

AMA. American Marketing Association.(2015). Recuperado 20 de Diciembre de 2018. https://www.ama.org/resources/Pages/Dictionary.aspx?dLetter=G

Fanjul, E., Iberglobal portal. Qué es la globalización. Recuperado el 10 de Mayo de 2019. http://iberglobal.com/index.php/escuela-de-comercio-exterior/1559-que-es-laglobalizacion 


\section{ACLARACIÓN}

"Declaro bajo juramento que esta tesis fue elaborada por mí, que no utilicé ningún otro material que no haya dado a conocer en las referencias y que no utilicé frases o párrafos de otros autores y que este trabajo de tesis nunca ha sido presentado ante un comité de evaluación de tesis y que no transgrede derechos de terceros."

Paola Chandler

NOTA: COLOCAR LA PRIMERA LETRA DE LOS SUBTITULOS EN MAYUSCULAS Y EL RESTO EN MINUSCULAS 